\title{
Recent trends in daily temperature extremes over northeastern Spain (1960-2006)
}

\author{
A. El Kenawy ${ }^{1,2}$, J. I. López-Moreno ${ }^{1}$, and S. M. Vicente-Serrano ${ }^{1}$ \\ ${ }^{1}$ Instituto Pirenaico de Ecologia - CSIC, Campus de Aula Dei, P.O. Box 13034, Zaragoza, 50059, Spain \\ ${ }^{2}$ Department of Geography, Mansoura University, Mansoura, Egypt
}

Received: 11 June 2010 - Revised: 30 June 2011 - Accepted: 10 July 2011 - Published: 27 September 2011

\begin{abstract}
Spatial and temporal characteristics of extreme temperature events in northeastern Spain have been investigated. The analysis is based on long-term, high-quality, and homogenous daily maximum and minimum temperature of 128 observatories spanning the period from 1960 to 2006. A total of 21 indices were used to assess changes in both the cold and hot tails of the daily temperature distributions. The presence of trends in temperature extremes was assessed by means of the Mann-Kendall test. However, the autocorrelation function (ACF) and a bootstrap methodology were used to account for the influence of serial correlation and cross-correlation on the trend assessment. In general, the observed changes are more prevalent in hot extremes than in cold extremes. This finding can largely be linked to the increase found in the mean maximum temperature during the last few decades. The results indicate a significant increase in the frequency and intensity of most of the hot temperature extremes. An increase in warm nights (TN90p: 3.3 days decade $^{-1}$ ), warm days (TX90p: 2.7 days decade ${ }^{-1}$ ), tropical nights (TR20: 0.6 days decade ${ }^{-1}$ ) and the annual high maximum temperature (TXx: $0.27{ }^{\circ} \mathrm{Cdecade}^{-1}$ ) was detected in the 47-yr period. In contrast, most of the indices related to cold temperature extremes (e.g. cold days (TX10p), cold nights (TN10p), very cold days (TN1p), and frost days (FD0)) demonstrated a decreasing but statistically insignificant trend. Although there is no evidence of a longterm trend in cold extremes, significant interdecadal variations were noted. Almost no significant trends in temperature variability indices (e.g. diurnal temperature range (DTR) and growing season length (GSL)) are detected. Spatially, the coastal areas along the Mediterranean Sea and the Cantabrian
\end{abstract}

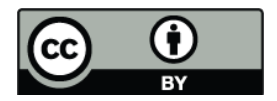

Correspondence to: A. El Kenawy (kenawy@ipe.csic.es)
Sea experienced stronger warming compared with mainland areas. Given that only few earlier studies analyzed observed changes in temperature extremes at fine spatial resolution across the Iberian Peninsula, the results of this work can improve our understanding of climatology of temperature extremes. Also, these findings can have different hydrological, ecological and agricultural implications (e.g. crop yields, energy consumption, land use planning and water resources management).

\section{Introduction}

During the second half of the 20th century, the globally averaged $2 \mathrm{~m}$ air temperature increased by $0.6^{\circ} \mathrm{C}$ (Folland et al., 2001). However, this warming was not spatially or temporally uniform. Typically, climate change detection is associated more often with the analysis of changes in extreme events than with changes in the mean (Katz and Brown, 1992). Extreme temperature events can impact many aspects of human life including: mortality, comfort, ecology, agriculture, and hydrology (Schindler, 1997; Ciais et al., 2005; Garcia-Herrera et al., 2005; Patz et al., 2005). For instance, the unusual summer heat wave of 2003 had a significant influence on numerous European communities (Christopher and Gerd, 2003; Luterbacher et al., 2004). Accordingly, the characterization of climate extremes can provide invaluable information for impact assessment studies, particularly those related to hydrological and environmental modeling.

Recently, substantial efforts have been made to estimate not only changes in mean temperature series, but also changes in the frequency, intensity, and duration of extreme events (Easterling et al., 2000; Jones et al., 2001; Frich et al., 2002; Klein Tank and Konnen, 2003; Kostopoulou and

Published by Copernicus Publications on behalf of the European Geosciences Union. 
Jones, 2005; Moberg and Jones, 2005; Vincent et al., 2005; Alexander et al., 2006; Moberg et al., 2006; Brown et al., 2008). These studies have analyzed temperature extremes at different spatial scales, ranging from the regional to the global. In general, most of the findings revealed a significant upward (downward) trend in the duration and frequency of hot (cold) extremes. For instance, Alexander et al. (2006) noted a global significant decrease in cold temperature extremes throughout the second half of the 20th century. Frich et al. (2002) also found positive trends in hot extremes at a broader spatial scale including: Europe, the USA, China, Canada and Australia. Nonetheless, the characteristics of temperature extremes are still incompletely understood at the regional scale, due to the lack of high-quality daily resolution data with a reasonable spatial coverage.

Over the last few decades, many studies have put a great deal of effort into exploring the behavior of temperature extremes in the Mediterranean region (e.g. Maheras et al., 1999; Della-Marta et al., 2007; Kuglitsch et al., 2010). However, little research on the variability of temperature extremes is available for the Iberian Peninsula. While numerous studies were conducted to trace spatial and temporal patterns of precipitation extremes in Iberia (e.g. Martin-Vide, 2004; Begueria-Portugues and Vicente Serrano, 2006; Costa and Soares; 2009; López-Moreno et al., 2010), there are very few assessments of trends in temperature extremes, especially at fine spatial resolution (e.g. Prieto et al., 2004; Brunet et al., 2007b; Bermejo and Ancell, 2009; Rodriguez-Puebla et al., 2010). Among these studies, Brunet et al. (2007b) assessed variability of temperature extremes in Spain over the course of the 20th century. They reported evidence of larger changes in high temperature extremes than in low temperature extremes. Based on daily data from 26 observatories coupled with a gridded dataset, Rodriguez-Puebla et al. (2010) has recently investigated spatial and temporal changes in warm days and cold nights across the Iberian Peninsula during 1950-2006. At the regional scale, Miro et al. (2006), as an example, reported a significant increase in the frequency of warm and extreme temperature days in Valencia from 1958 to 2003. In this context, few studies have analyzed changes in daily temperature extremes in the study domain. Among these works, Lana and Burgueño (1996) examined the spatial distribution of extreme minimum temperature in Catalonia (NE Spain) during the cold season (December-March). More recently, Burgueño et al. (2002) analyzed daily temperature extremes at the Fabra station (Barcelona). However, most of these studies employed a coarse dataset in terms of spatial coverage. Thus, we still believe that a more detailed analysis of temperature extremes is still demanded for NE Spain. From both spatial and temporal perspectives, our dataset can provide a more reliable analysis of temperature extremes. In particular, this dataset can enhance the grid resolution of any climatic study to verify future simulations of extreme events under different scenarios.

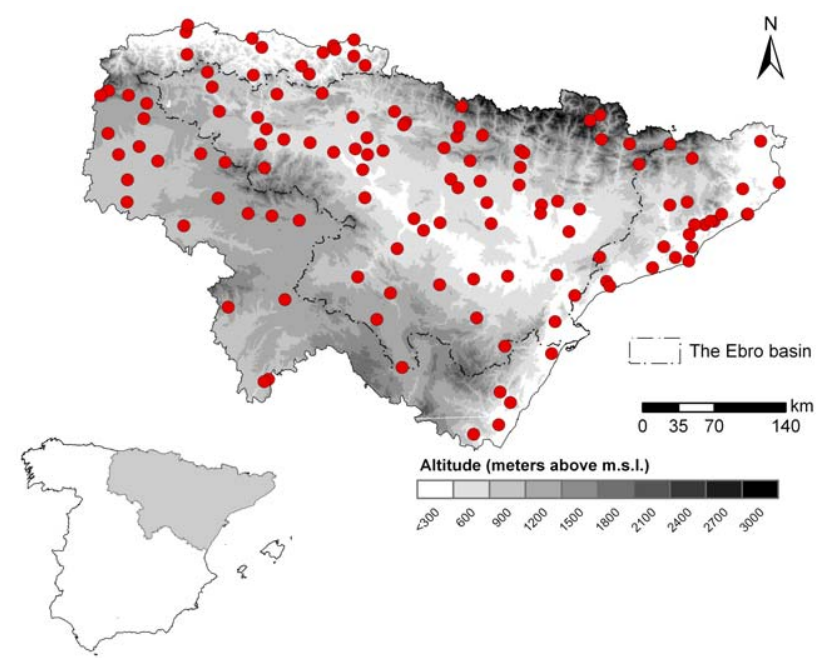

Fig. 1. Location of the study area and spatial distribution of the meteorological stations.

The main goal of the present study is to analyze trends in daily maximum and minimum temperature in northeastern Spain using 21 extreme temperature indices. The spatial and temporal variability of these indices are examined using daily temperature data from 128 observatories covering the period from 1960 to 2006. This dataset represents the most complete record and the densest network of daily temperature observatories in the study area. Therefore, this work aims to reveal novel information about the variability of extreme temperatures in the Iberian Peninsula and can therefore contribute to better understanding of the impact of climate change on it. Moreover, the gained results can be placed in a larger climate context, providing insights into the long-term behavior of temperature extremes in the Mediterranean region and southwestern Europe.

\section{Data and methods}

\subsection{Study area}

The study area is an 18-province region located in NE Spain (Fig. 1). Geographically, it is situated between the latitudes of $39^{\circ} 43^{\prime} \mathrm{N}$ and $43^{\circ} 29^{\prime} \mathrm{N}$, and the longitudes of $05^{\circ} 01^{\prime} \mathrm{W}$ and $03^{\circ} 17^{\prime} \mathrm{E}$, with an area of about $159424 \mathrm{~km}^{2}$. The study region is characterized by its complex physiography. As depicted in Fig. 1, the Ebro valley is a unique physiographical unit enclosed by mountainous belts; the Catalan coastal range, the Cantabrian range, and the Pyrenees being the most well-known. The terrain complexity leads to diverse climatic regimes with dominance of continental conditions in the central regions. The climate is particularly affected by maritime influences from the Mediterranean Sea in the East and the Cantabrian Sea in the Northwest. 


\subsection{Data description}

Changes in temperature extremes were analyzed using daily temperature time series from 128 observatories spanning the period 1960-2006. The original dataset was provided by the Spanish Meteorological Agency (Agencia Estatal de Meteorologia). In addition to data availability, the quality and homogeneity of the temperature time series are prerequisites for detailed attribution of extreme events. Therefore, a newly compiled, quality- controlled, and homogeneity-tested dataset was recently developed from the original dataset. Quality control is needed to assure the reliability of climate data. Therefore, the raw data were subjected to several quality control checks. First, the data were screened for any erroneous data that resulted from archiving, transcription or digitizing processes (e.g. $T_{\min } \geq T_{\max }$, non-existent dates). Each independent time series was then checked carefully for external consistency following Stepanek et al. (2009). This procedure helped eliminate outliers that notably differed from nearby observatories while valid records of temperature extremes are maintained. Also, homogenous time series are essential to assess changes in temperature extremes. In fact, inhomogenities can make the data unrepresentative of the real climate variations and lead to invalid conclusions. Accordingly, the temperature series were tested for presence of inhomogeneities. To accomplish this task, a well-defined monthly reference series was created for each testable series using the best correlated data from neighboring sites following the methodology of Peterson and Easterling (1994). Then, three relative homogeneity tests were applied to identify all possible breakpoints in the series, including: the Standard Normal Homogeneity Test (SNHT) for a single break (Alexandersson 1986), the Easterling and Peterson two-phase regression technique (Easterling and Peterson, 1995), and the Vincent method (Vincent, 1998). Testing homogeneity was conducted for monthly, seasonal and annual time series at the $95 \%$ confidence level using AnClim software (Stepanek, 2004). When a statistically significant breakpoint was identified, a correction model was applied to adjust the detected breaks. A monthly correction factor based on the combined results of all homogeneity tests was computed and then interpolated to daily data following the approach of Sheng and Zwiers (1998). At this end, the final dataset was relatively homogenous and free from the effects of non-climatic factors (e.g. changes in locations, instruments, observers, observing practices, and surrounding environments). A more complete description of the development of this dataset is given by El Kenawy et al. (2010). Given that the analysis of extreme events is very sensitive to the presence of missing values in the series, our analysis was restricted to those stations with non-missing data between 1960 and 2006. Figure 1 shows the spatial distribution of temperature observatories used in this study. As illustrated, the stations have a reasonable spatial coverage, and therefore they can adequately the capture regional variability of temperature extremes in the study domain.

\subsection{Definition of temperature indices}

Climate change may affect extreme temperatures in different ways (e.g. frequency, intensity, persistence). Thus, there is no unique definition of an extreme event as several definitions have been proposed and applied in recent works (e.g. Alexander et al., 2006; IPCC, 2007). Accordingly, it is beneficial to apply various indices to obtain a broad and more reliable picture of temperature behavior in the study area. In this work, a set of 21 indices were used to examine spatial and temporal variability of temperature extremes. Table 1 provides a detailed description of these indices grouped into three main categories. All these indices were calculated on an annual basis for each independent time series during the 47-yr period (1960-2006). As indicated in Table 1 , the indices were defined in different ways, varying from a certain fixed threshold (e.g. summer days (SU25) and tropical nights (TR20)) to a percentile-based threshold (e.g. very cold days (TN1p), warm days (TX90p), and cold days (TX10p)). In general, the percentile-based indicators are defined as days passing the warmest/coldest long-term percentiles. In this work, the percentiles were computed at each site for the entire period from 1 January 1960 to 31 December 2006 to account for cold and hot temperatures. This is a commonly used method to determine extreme values in climatology (Alexander et al., 2006; Trenberth et al., 2007; IPCC, 2007). These definitions are objective, site-independent, and facilitate direct comparisons between different regions (Choi et al., 2009). Our study area is a typical case, whereby complex terrain and diverse climates are evident. For instance, an exploratory screening of the 90th percentile of maximum temperature calculated from 1 January 1960 to 31 December 2006 revealed considerable spatial differences. The values varied from $20^{\circ} \mathrm{C}$ at Port del Comte (Lleida) to $34.8^{\circ} \mathrm{C}$ at Salto de Zorita (Guadalajara). On the other hand, we also used indices based on the number of days per years that exceeded certain widely used thresholds of temperature extremes. This is the case for the summer days (SU25: $T_{\max }>25^{\circ} \mathrm{C}$ ), tropical nights (TR20: $T_{\min }>20^{\circ} \mathrm{C}$ ), frost days $\left(\mathrm{FD}, T_{\min }<0^{\circ} \mathrm{C}\right.$ ), and ice days (ID: $T_{\max }<0^{\circ} \mathrm{C}$ ). Calculation of temperature indices in this way is considered a straightforward and appropriate approach for climate impact assessment, particularly at fine spatial scales. These definitions can be more valuable when the defined thresholds have physical, hydrological or biological meaning (Politano, 2008). Lastly, some other indices were used to analyze the relationship between maximum and minimum temperature. This group of indices includes, as examples, intra-annual extreme temperature range (Intr), diurnal temperature range (DTR), and standard deviation of the daily mean (Stdev). As an example, the Stdev index is used 
Table 1. List of all temperature indices used in this study and their definitions.

\begin{tabular}{|c|c|c|c|}
\hline & Index & Definition & Unit \\
\hline \multirow{8}{*}{ 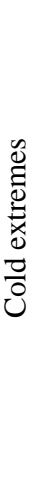 } & Cold days $\left(\mathrm{TX} 10_{\mathrm{p}}\right)$ & $\begin{array}{l}\text { Percentages of days with maximum temperatures lower than the 10th } \\
\text { percentile. }\end{array}$ & days \\
\hline & Cold nights ( TN10 $)$ & $\begin{array}{l}\text { Percentages of days with minimum temperatures lower than the } 10 \text { th } \\
\text { percentile. }\end{array}$ & days \\
\hline & Frost days (FD0) & Number of days with minimum temperature $<0^{\circ} \mathrm{C}$ per year. & days \\
\hline & Ice days (ID0) & Number of days with maximum temperature $<0{ }^{\circ} \mathrm{C}$ per year. & days \\
\hline & Coldest night $(\mathrm{CN})$ & Lowest daily minimum temperature. & ${ }^{\circ} \mathrm{C}$ \\
\hline & Very cold days $\left(\mathrm{TN} 1_{\mathrm{p}}\right)$ & Number of days with minimum temperature $<1$-th percentile per year. & days \\
\hline & Annual high minimum $\left(\mathrm{TN}_{x}\right)$ & Maximum value of monthly minimum temperature. & ${ }^{\circ} \mathrm{C}$ \\
\hline & Annual low minimum $\left(\mathrm{TN}_{n}\right)$ & Minimum value of monthly minimum temperature. & ${ }^{\circ} \mathrm{C}$ \\
\hline \multirow{8}{*}{ 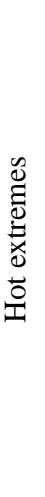 } & Warm days $(\mathrm{TX} 90 \mathrm{p})$ & $\begin{array}{l}\text { Percentages of days with maximum temperatures higher than the 90th } \\
\text { percentile. }\end{array}$ & days \\
\hline & Warm nights (TN90p) & $\begin{array}{l}\text { Percentages of days with minimum temperatures higher than the 90th } \\
\text { percentile. }\end{array}$ & days \\
\hline & Summer days (SU25) & Number of days with maximum temperature $>25^{\circ} \mathrm{C}$ per year. & days \\
\hline & Warmest day (WD) & Highest daily maximum temperature. & ${ }^{\circ} \mathrm{C}$ \\
\hline & Very hot days $\left(\mathrm{TX} 99_{\mathrm{p}}\right)$ & Number of days with maximum temperature $>99$-th percentile per year. & days \\
\hline & Tropical nights (TR20) & Number of days with minimum temperature $>20^{\circ} \mathrm{C}$ per year. & days \\
\hline & Annual high maximum $\left(\mathrm{TX}_{x}\right)$ & Maximum value of monthly maximum temperature. & ${ }^{\circ} \mathrm{C}$ \\
\hline & Annual low maximum $\left(\mathrm{TX}_{n}\right)$ & Minimum value of monthly maximum temperature. & ${ }^{\circ} \mathrm{C}$ \\
\hline \multirow{5}{*}{ 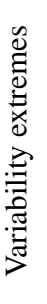 } & Temperature sums $\left(T_{\text {sums }}\right)$ & Sum of $T_{\max }$ days $>17^{\circ} \mathrm{C}$-days $T_{\max }<17^{\circ} \mathrm{C}$ & ${ }^{\circ} \mathrm{C}$ \\
\hline & Intra-annual extreme temperature range (Intr) & Difference between the highest TX and the lowest TN in the year. & ${ }^{\circ} \mathrm{C}$ \\
\hline & Diurnal temperature range (DTR) & Monthly mean difference between TX and TN. & ${ }^{\circ} \mathrm{C}$ \\
\hline & Standard deviation of $T_{\text {mean }}(\mathrm{Stdev})$ & Standard deviation of daily mean temperature from the $T_{\text {mean }}$ normal. & ${ }^{\circ} \mathrm{C}$ \\
\hline & Growing season length (GSL) & $\begin{array}{l}\text { Annual count of days between the first span of at least } 6 \text { days with } \\
T_{\text {mean }}>5^{\circ} \mathrm{C} \text {. and first span after } 1 \text { July of } 6 \text { days with } T_{\text {mean }}<5{ }^{\circ} \mathrm{C} \text {. }\end{array}$ & days \\
\hline
\end{tabular}

as a measure of the departure from the mean condition. It is generally assumed that Stdev values tend to be higher during warm years. Therefore, it can be a good indicator of temperature interannual variability under a global warming scenario.

In practice, all the selected indices are relevant to the Spanish context. They encompass the most important aspects of temperature extremes including: intensity, frequency, and variability. In addition, they summarize characteristics of both moderate weather events (e.g. SU25, TX90p, and TN10p) and extremely severe events (e.g. TX99p and TN1p). Also, these indicators have been validated by the World Meteorological Organization (WMO, 2009), the European Climate Assessment (ECA) (http://eca.knmi.nl/), and the European project of Statistical and Regional dynamical Downscaling of Extremes (STARDEX EU) for extreme temperature research (http://www.cru.uea.ac.uk/projects/stardex/).

\subsection{Trends calculation}

The linear trend in the derived temperature indices was computed using the ordinary least squares (OLS) method. The significance of the trend was assessed using the Mann-Kendall's tau test at the $95 \%$ significance level (p-value <0.05). The Mann-Kendall statistic is a rank-based nonparametric test, which is advantageous compared to parametric tests such as Pearson's correlation coefficient. This is mainly because it is robust to outliers and does not assume an underlying probability distribution of the data series (Moberg et al., 2006). As a result, this statistic has been widely used in climatological and hydrological applications (e.g. Zhang et al., 2005; Choi et al., 2009). It is worthwhile indicating that the trend assessment was conducted for each individual observatory in the period 1960-2006. In addition, the trend 
was also calculated for the regional series obtained for the whole region for each particular index. The rationale behind this procedure was to test whether the detected trend in temperature extremes at each station occurred due to local conditions or revealed a large-scale spatial coherence. In this regard, the regional series were created on the basis of a weighted average of all values in the temperature observatories across the study area. The weight was a function of the surface represented by each observatory according to the Thiessen polygon method (Jones and Hulme, 1996). This approach controls the bias that can be yielded from averaging regions with a higher spatial density of observing stations.

\subsection{Assessment of uncertainty in trends calculation}

Previous studies dealing with changes in climate extremes have investigated the possible sources of uncertainty in trend assessment (e.g. serial correlation, cross-correlation, data inhomogenities, and the period of investigation) (Caussinus and Mestre, 2004; Moberg and Jones, 2005; Zhang et al., 2005). In the following section, we address the possible influence of serial correlation and spatial autocorrelation on trend assessment. These issues have been extensively discussed in many climatological (e.g. Zhang et al., 2005; Vincent et al., 2010) and hydrological (e.g. Yue et al., 2002; Yue and Wang, 2004) applications.

\subsubsection{Serial correlation}

Typical time series data are usually statistically dependent due to the existence of non-random components, such as persistence, cycles or trends (WMO, 1966). The Mann-Kendall statistic is not robust against serial correlation, which often occurs in climatic time series, in that a positive serial correlation in a time series can incorrectly increase the probability of rejecting the null hypothesis $\left(\mathrm{H}_{0}\right)$ of no trend (Yue and Wang, 2002). The autocorrelation function (ACF) has been used to eliminate the effects of serial correlation prior to trend assessment. Box and Jenkins (p. 33, 1970) suggested use of the ACF when the number of values $(n)$ is at least 50 and the number of lags is at most $n / 4$. When the lag-1 correlation coefficient was significant at the $95 \%$ level $(p<0.05)$, the presence of serial correlation was verified and removed from the detrended series prior to performing the trend analysis following the approach described by Burn and Cunderlik (2004).

\subsubsection{Cross-correlation}

The presence of cross-correlation in climatological datasets can likely influence the accuracy of trends assessment (Lettenmaier at al., 1994), as it increases the probability of detecting a trend in the time series while there is no trend (Douglas et al., 2000). Further discussion of possible impacts of crosscorrelation on trend assessment can be found in Lettenmaier at al. (1994) and Damowski and Bougadis (2003). In the literature, numerous bootstrap resampling schemes have been developed to account for spatial correlation in climatological datasets (Lettenmaier at al., 1994; Douglas et al., 2000). In this work, a bootstrap resampling procedure was applied to evaluate the significance of trends at both the global and local levels. The rationale behind this procedure was to determine whether local changes or trends observed at individual observatories are related to the global (field) trend obtained for the whole region. This procedure is summarized in the following steps:

1. A set of $10^{3}$ Monte Carlo simulations with a length of 47-yr was generated for each time series at random from the observed data (1960-2006). Following Kundzewick and Robson (2000), the simulated time series were extracted from the original dataset by replacement with equal probability.

2. The statistical significance of each time series in the original and the simulated datasets was assessed using the Mann-Kendall statistic. The percentage of the trends that are significant at each $\alpha \%$ level was defined. Then, the global significance level was computed as the arithmetic mean of the local significance levels at the individual observatories for each index.

3. The probability of obtaining a trend in the resampled series was compared with the original data for each index. Then, the cumulative distribution function (cdf) was used to compare between the observed and the simulated datasets at specific levels of statistical significance.

Douglas et al. (2000) applied a similar approach to define the global significance for low flow rates of streams in the USA.

\section{Results}

\subsection{Randomness testing}

The presence of serial correlation in time series can affect the ability of the Mann-Kendall's test to correctly assess the significance of trends. In our study, the ACF results confirm that a majority of the stations do not show significant serial correlation at the lag-1. A large proportion of the time series is serially independent and does not exhibit short-term persistence. Figure 2 illustrates an example of the TX10p time series for the observatory of the Barcelona Airport. As presented, the lag-1 serial correlation coefficient was insignificant at $p<0.05$. This suggests that the series is free from serial correlation. Given that temperature series show low persistence at the annual time scale with respect to a monthly or seasonal time scale, the observed lack of serial correlation 


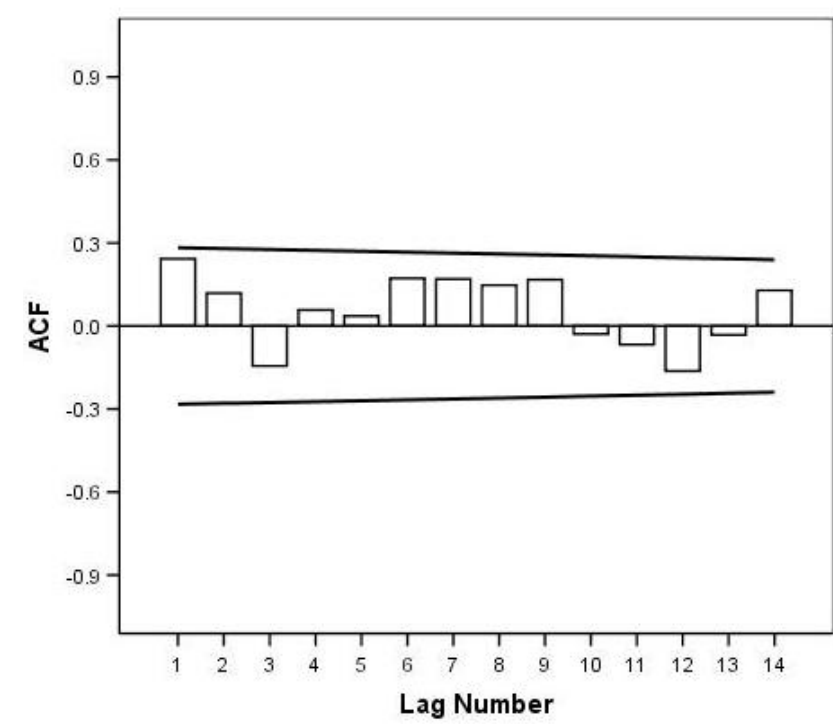

Fig. 2. Autocorrelation function for the cold days (TX10p) time series of the observatory of "airport of Barcelona" obtained by taking 14-yr differences (solid line refers to the upper and lower limit of the $95 \%$ significance level given by $\pm 1.96\left(\frac{1}{\sqrt{n}}\right)$ where $n=47$ for the period 1960-2006.

in our time series can be expected. In a few cases, however, the time series showed significant serial correlation. In such cases, the prewhitening procedure (Yue et al., 2002) was used to limit the effect of serial correlation before applying the trend test. One obvious example corresponding to the WD time series in Amurrio observatory (Alava) is given in Fig. 3. The time series presented a significant lag-1 serial correlation coefficient (Fig. 3a), since more than $5 \%$ of the sample autocorrelations exceeded the upper confidence limit. To eliminate the serial correlation, the pre-whitening procedure was applied and the Mann-Kendall test was undertaken for the pre-whitened series. Figure $3 b$ depicts the lag correlations after removing the effect of the serial correlation.

To account for the possible impact of cross-correlation on trend assessment, the cumulative probability distribution functions (cdf) of both the Monte Carlo simulations and the observed series against different statistical significance levels are plotted in Fig. 4. Overall, the results indicate that the influence of regional cross-correlation on trend assessment had negligible impact. A comparison of the field significance of the observed and resampled data confirms that the empirical probability distribution of the observed data is smaller than that of the simulated data at a p-value of 0.025 , and larger at a p-value of 0.975 . This simply implies that the observed data are statistically significant at $\mathrm{p}$-value $<0.05$. In addition, the total number of series with significant trends at the $95 \%$ confidence level was generally larger than those obtained from the $10^{3}$ Monte Carlo runs. This suggests that
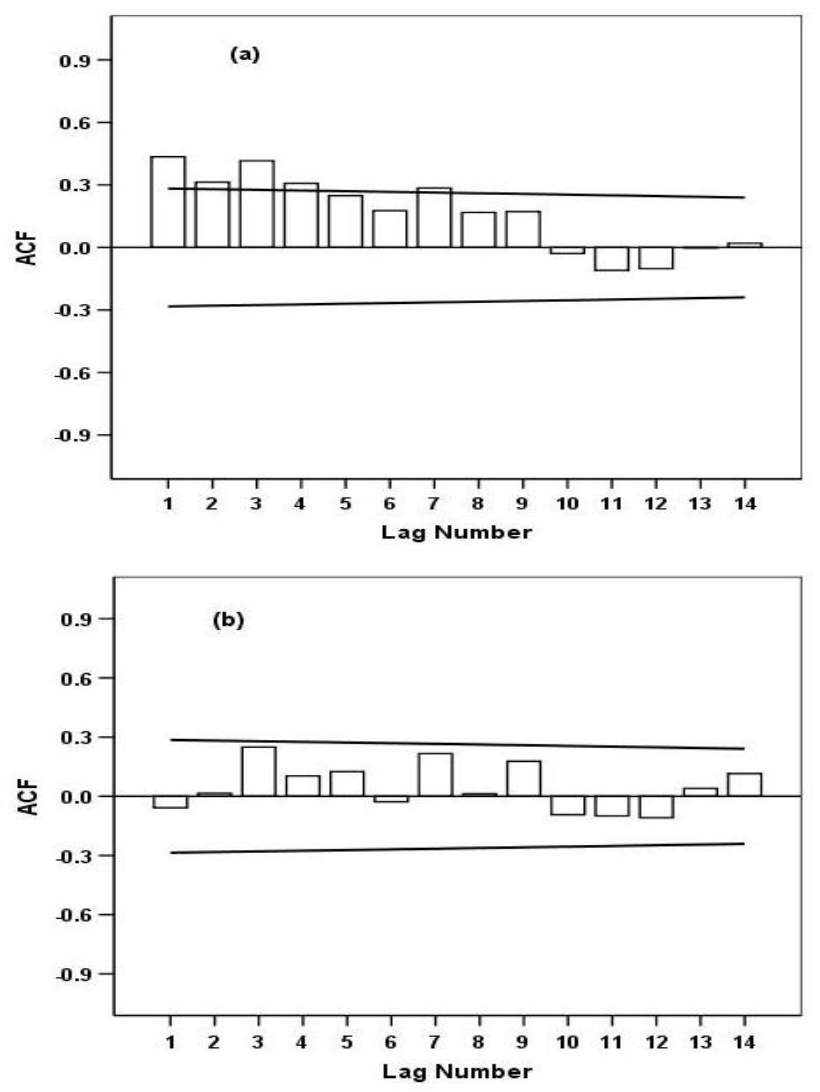

Fig. 3. Autocorrelation function for the warmest day (WD) time series of the observatory of Amurrio (Alava province) (a) before and (b) after application of the prewhitening procedure (solid line refers to the upper and lower limit of the $95 \%$ significance level given by $\pm 1.96\left(\frac{1}{\sqrt{n}}\right)$ where $n=47$ for the period $1960-2006$.

the observed trends in the temperature extremes are greater than the number of the trends that are expected to occur by chance. The pattern of the obtained trends at the individual observatories is thus independent of climate noise and does reflect a global trend. Overall, it can be concluded that the local trends obtained from the original dataset are very consistent with those observed at the global scale. Taking this finding together with the serial correlation results, it can be implied that statistical significance of trend estimates can be used with more confidence.

\subsection{Spatial and temporal variability of temperature extremes}

This section gives an overview of trend results for each of the investigated indices. Table 2 summarizes the results from the application of the Mann-Kendall test. Figures 5, 8, and 11 show the spatial patterns of the trend for each index in terms of the direction (sign) and statistical significance. 

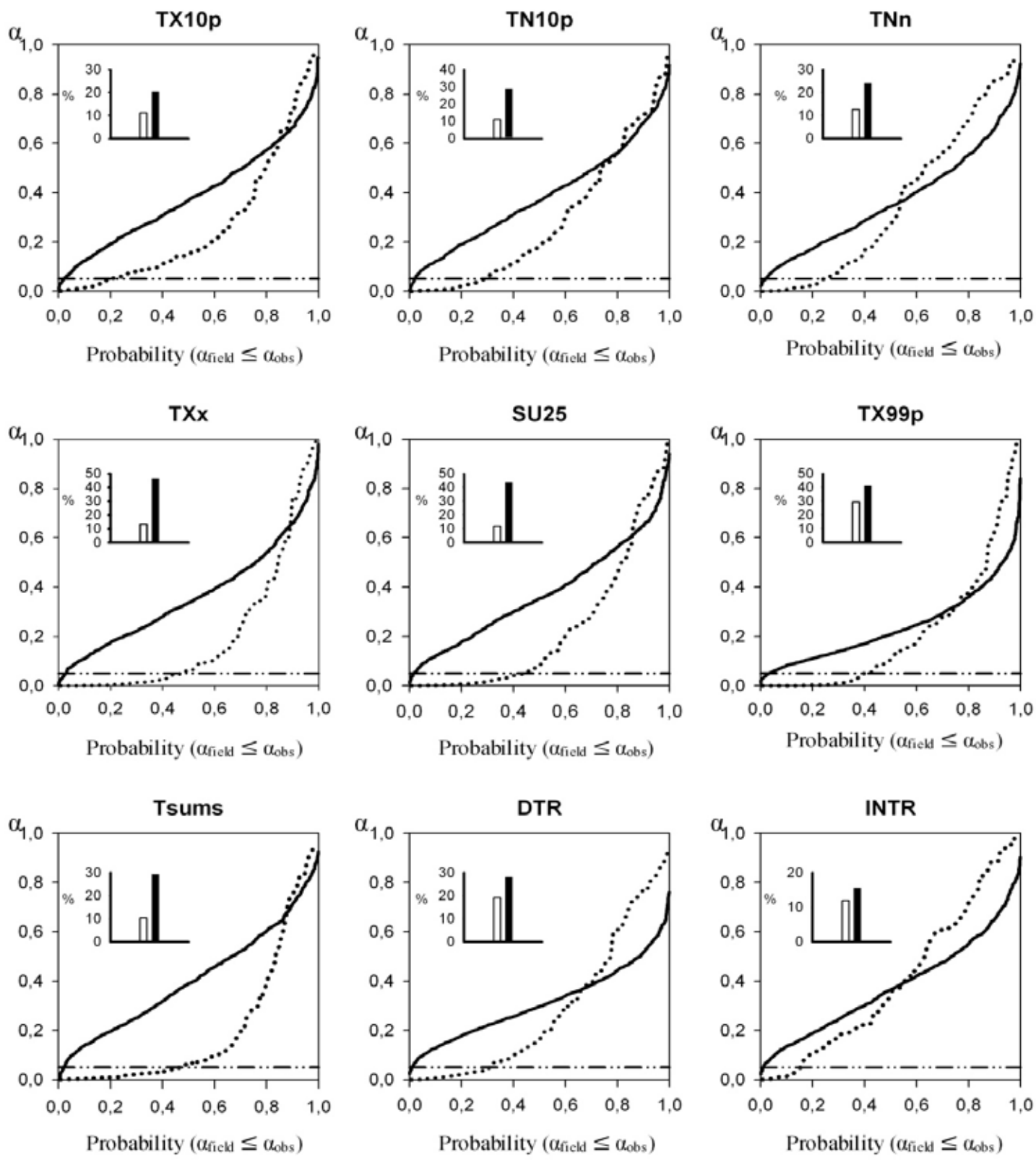

$$
\begin{array}{ll} 
& \text { Resampled data (spatially correlated) } \\
\ldots \ldots \ldots . . & \text { Observed data (spatially independent) } \\
\ldots \cdots \cdots & P \text { at } 0,05
\end{array}
$$

Fig. 4. The empirical cumulative distribution function (cdf) of the significance levels of the trends for the resampled and observed data for a selected number of indices. Bar lines in the upper panel show percentage of the observed series $(\boldsymbol{\square})$ and the resampled series $(\square)$ with statistically significant trend at $p<0.05$.

\subsubsection{Changes in hot extremes}

Table 2 summarizes the results of the Mann-Kendall test for hot temperature indices. As indicated, there is a general upward tendency in most of the hot extremes for both frequency and intensity indices. On average, this increase is more evident for the indices of warm nights (TN90p) (96.1\% of observatories), warm days (TX90p) (93.8\%), and the annual high of maximum temperature $(91.4 \%)$. However, hot extremes related to night-time showed more significant trends compared with day-time indices. For example, tropical nights (TR20) and warm nights (TN90p) showed an 
Table 2. Results of trend analysis for cold, hot and variability extremes (significance is assessed at the $95 \%$ level). Abbreviations of the indices correspond to those in Table 1 .

\begin{tabular}{|c|c|c|c|c|c|c|c|}
\hline \multirow[t]{2}{*}{ Category } & \multirow[t]{2}{*}{ Index } & \multicolumn{3}{|c|}{ Positive } & \multicolumn{3}{|c|}{ Negative } \\
\hline & & Sig. & Non-Sig. & Total (\%) & Sig. & Non-Sig. & Total (\%) \\
\hline \multirow[t]{8}{*}{ Cold extremes } & TX10p & 0.8 & 13.3 & 14.1 & 19.5 & 66.4 & 85.9 \\
\hline & TN10p & 3.1 & 22.7 & 25.8 & 25.8 & 48.4 & 74.2 \\
\hline & FD0 & 1.6 & 24.2 & 25.8 & 27.3 & 46.9 & 74.2 \\
\hline & ID0 & 0.0 & 14.8 & 14.8 & 16.4 & 68.8 & 85.2 \\
\hline & $\mathrm{CN}$ & 18.8 & 42.2 & 61.0 & 2.3 & 36.7 & 39.0 \\
\hline & TN1p & 0.8 & 34.3 & 35.1 & 17.2 & 47.7 & 64.9 \\
\hline & TNx & 69.5 & 24.2 & 93.7 & 0.8 & 5.5 & 6.3 \\
\hline & $\mathrm{TNn}$ & 19.5 & 44.5 & 64.0 & 4.7 & 31.3 & 36.0 \\
\hline \multirow[t]{8}{*}{ Hot extremes } & TX90p & 56.3 & 37.5 & 93.8 & 0.0 & 6.2 & 6.2 \\
\hline & TN90p & 73.4 & 22.7 & 96.1 & 1.6 & 2.3 & 3.9 \\
\hline & SU25 & 43.8 & 42.2 & 86.0 & 0.0 & 14.0 & 14.0 \\
\hline & WD & 28.9 & 50 & 78.9 & 1.6 & 19.5 & 21.1 \\
\hline & TX99p & 39.8 & 42.2 & 82.0 & 1.6 & 16.4 & 18.0 \\
\hline & TR20 & 47.7 & 38.3 & 86.0 & 1.6 & 12.5 & 14.1 \\
\hline & TXx & 46.1 & 45.3 & 91.4 & 0.0 & 8.6 & 8.6 \\
\hline & TXn & 32.0 & 56.3 & 88.3 & 0.8 & 10.9 & 11.7 \\
\hline \multirow[t]{5}{*}{ Variability extremes } & $T_{\text {sums }}$ & 46.9 & 46.9 & 93.8 & 0.0 & 6.2 & 6.2 \\
\hline & Intr & 12.5 & 43 & 55.5 & 3.1 & 41.4 & 44.5 \\
\hline & DTR & 12.5 & 36.7 & 49.2 & 15.6 & 35.2 & 50.8 \\
\hline & Stdev & 15.6 & 57.1 & 72.7 & 0.0 & 27.3 & 27.3 \\
\hline & GSL & 14.8 & 52.3 & 67.1 & 1.6 & 31.3 & 32.9 \\
\hline
\end{tabular}

upward trend in 47.7 and $73.4 \%$ of the observatories, respectively. In contrast, warmest day (WD), very hot days (TX99p), and summer days (SU25) reached the significance level only in $28.9,39.8$, and $43.8 \%$ of the observatories, respectively. This finding demonstrates that the cold tail of temperature distribution during the summer months increased more rapidly than the hot tail. Table 2 also indicates that more observatories $(46.1 \%)$ showed statistically significant trends in the annual high maximum temperature (TXx) with respect to the annual low maximum temperature (TXn) $(32 \%)$. This implies more increase in maximum temperature in summer than in winter over the period from 1960 to 2006. The results of a cross-tabulation analysis to explore relationships among pairs of hot temperature indices in terms of their temporal evolution are given in Table 3. As presented, the trend direction (sign) for most of the frequency indices showed a relatively high agreement between the signs of the trends. For instance, warm days (TX90p) exhibited the same direction of trends of summer days (SU25), very hot days (TX99p) and tropical nights (TR20) in 76.6, 74.2 and $61.7 \%$ of observatories respectively. The same behavior has also been confirmed between intensity indices (e.g. TXx and WD).

Figure 5 shows the spatial patterns of hot temperature trends. While most of the observatories in the study domain showed an upward tendency, considerable regional differences are revealed. The coastal areas along the Cantabrian Sea and the Mediterranean Sea mainly exhibited the largest warming, whereas many of the continental areas showed insignificant trends. This spatial structure of the trends is evident for indices related to both day-time hot extremes (e.g. TX90p, WD, SU25, and TX99p) and night-time hot extremes (TN90p and TR20). Nevertheless, a pattern of positive trends in night-time extremes was also found over the Ebro valley, which is not shown for day-time extremes. Figure $6 \mathrm{a}-\mathrm{c}$ reveals differences in the temporal evolution of warm nights (TN90p) at three different observatories. As illustrated, there was a very strong upward trend at Bilbao Airport observatory along the Cantabrian Sea (7.3 days decade ${ }^{-1}$ ) and Blanes observatory on the Mediterranean Sea (6.57 days decade ${ }^{-1}$ ). In contrast, the mainland observatory of Zaragoza Airport experienced less warming (3.29 days decade ${ }^{-1}$ ). This reveals considerable spatial differences in the behavior of hot extremes.

Figure 7 illustrates the regional series of each hot extreme index. In agreement with the upward tendency exhibited for most of the indices at the station-based level, an increasing trend in the regional series of warm days (TX90p), warm nights (TN90p), very hot days (TX99p), and tropical nights (TR20) can also be expected. As illustrated 

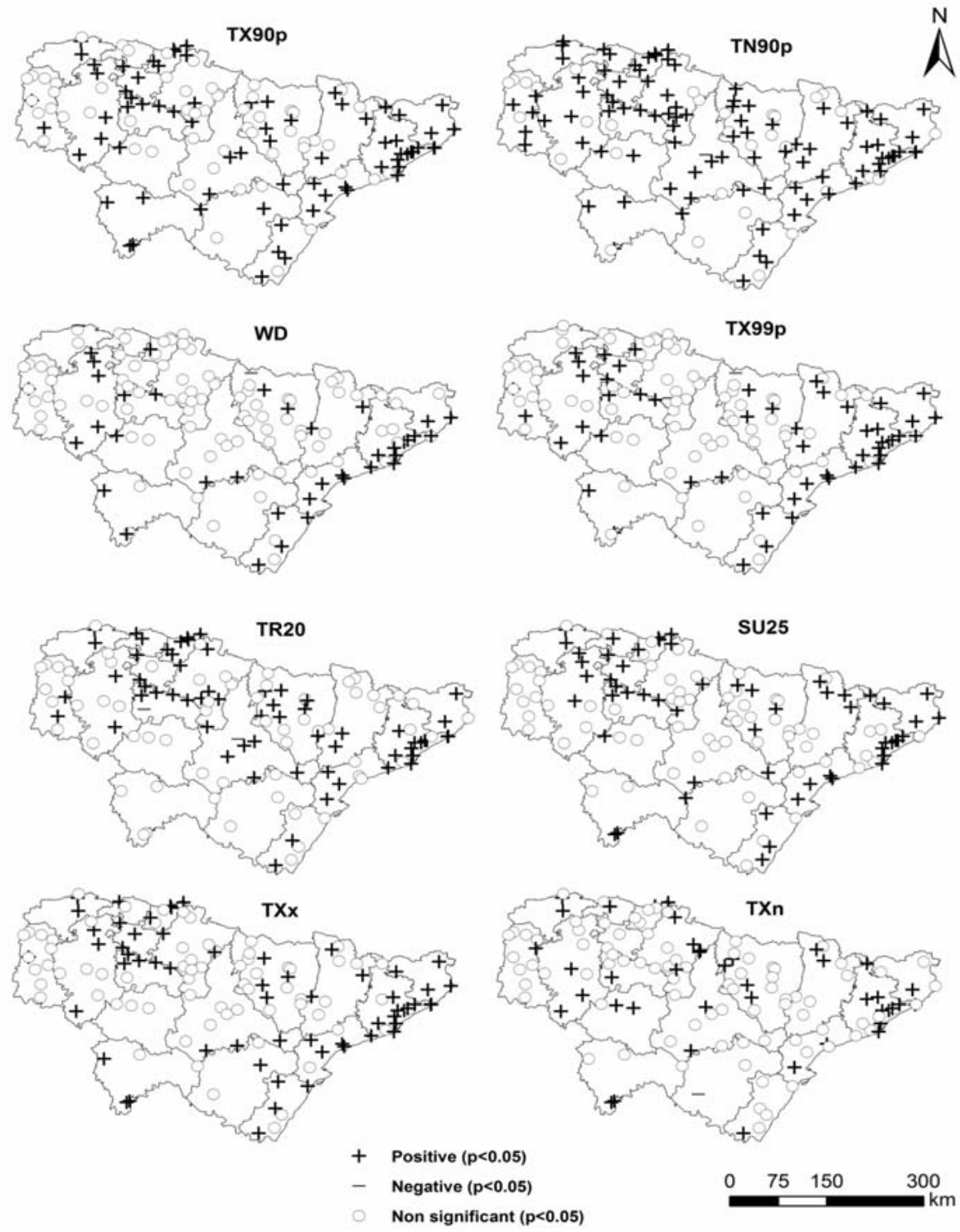

Fig. 5. Spatial distribution of the trends in hot extreme indices over the period 1960-2006.

in Fig. 7, the regional series suggest an upward tendency for 1960-2006, statistically significant for most of the indices. The strongest warming was mainly pertinent to warm nights (TN90p) and warm days (TX90p). The regional trends indicate that the warm days (TX90p) and warm nights (TN90p) increased significantly by 0.74 (2.7 days decade ${ }^{-1}$ ) and $0.91 \%$ (3.3 days decade ${ }^{-1}$ ), respectively. In contrast, tropical nights (TR20) and summer days (SU25) showed less warming, with a rate of 0.61 and 2.2 days decade ${ }^{-1}$, respectively. As illustrated in Fig. 7, most of the warming trends in TX90p, TN90p, TX99p, and TR20 occurred during the last two decades with an unusual peak in 2003. However, a gradual increasing trend was observed for TXx and TXn from 1960 to 2006.

\subsubsection{Changes in cold extremes}

Table 2 shows the trend results of the cold temperature indices. In general, it is evident that most of indices corresponding to frequency of cold extremes showed negative trends, though statistically insignificant in most observatories. For instance, 85.9, 85.2 and $74.2 \%$ of the observatories exhibited a declining tendency in cold days (TX10p), ice days (ID0), cold nights (TN10P), and frost days (FD0), respectively. By contrast, the indices corresponding to the intensity of cold extremes, including the coldest night $(\mathrm{CN})$ and the annual low minimum temperature (TNn) showed statistically significant trends in fewer observatories. Among all indices, the annual high minimum temperature (TNx) was 
Table 3. The association between pairs of hot and variability extreme indices with respect to the sign of the trends at the $95 \%$ level (statistically positive, statistically negative, and statistically insignificant). Numbers indicate sign coincidences for each pair of indices.

\begin{tabular}{|c|c|c|c|c|c|c|c|c|c|c|c|c|c|}
\hline Index & TX90p & TN90p & SU25 & WD & TX99p & TR20 & TXx & TXn & $T_{\text {sums }}$ & Intra & Stdev & GSL & DTR \\
\hline TX90p & & 65.6 & 76.6 & 63.3 & 74.2 & 61.7 & 77.3 & 54.7 & 71.9 & 50 & 46.9 & 49.2 & 40.6 \\
\hline TN90p & & & 53.1 & 41.4 & 52.3 & 66.4 & 53.9 & 37.5 & 59.4 & 29.7 & 29.7 & 32.0 & 26.6 \\
\hline SU25 & & & & 66.4 & 69.5 & 52.3 & 74.2 & 59.4 & 71.9 & 54.7 & 59.4 & 60.2 & 47.7 \\
\hline WD & & & & & 85.9 & 55.5 & 73.4 & 57.0 & 59.4 & 75.8 & 68.0 & 65.6 & 53.1 \\
\hline TX99p & & & & & & 51.6 & 78.1 & 55.5 & 65.6 & 66.4 & 61.7 & 59.4 & 49.2 \\
\hline TR20 & & & & & & & 62.5 & 49.2 & 53.9 & 47.7 & 47.7 & 51.6 & 46.9 \\
\hline TXx & & & & & & & & 57.0 & 68.0 & 57.0 & 60.2 & 57.8 & 46.1 \\
\hline TXn & & & & & & & & & 53.1 & 56.3 & 53.9 & 71.1 & 57.0 \\
\hline$T_{\text {sums }}$ & & & & & & & & & & 53.9 & 56.3 & 53.9 & 44.5 \\
\hline Intra & & & & & & & & & & & 75 & 72.7 & 62.5 \\
\hline Stdev & & & & & & & & & & & & 71.9 & 61.7 \\
\hline GSL & & & & & & & & & & & & & 60.2 \\
\hline DTR & & & & & & & & & & & & & \\
\hline
\end{tabular}
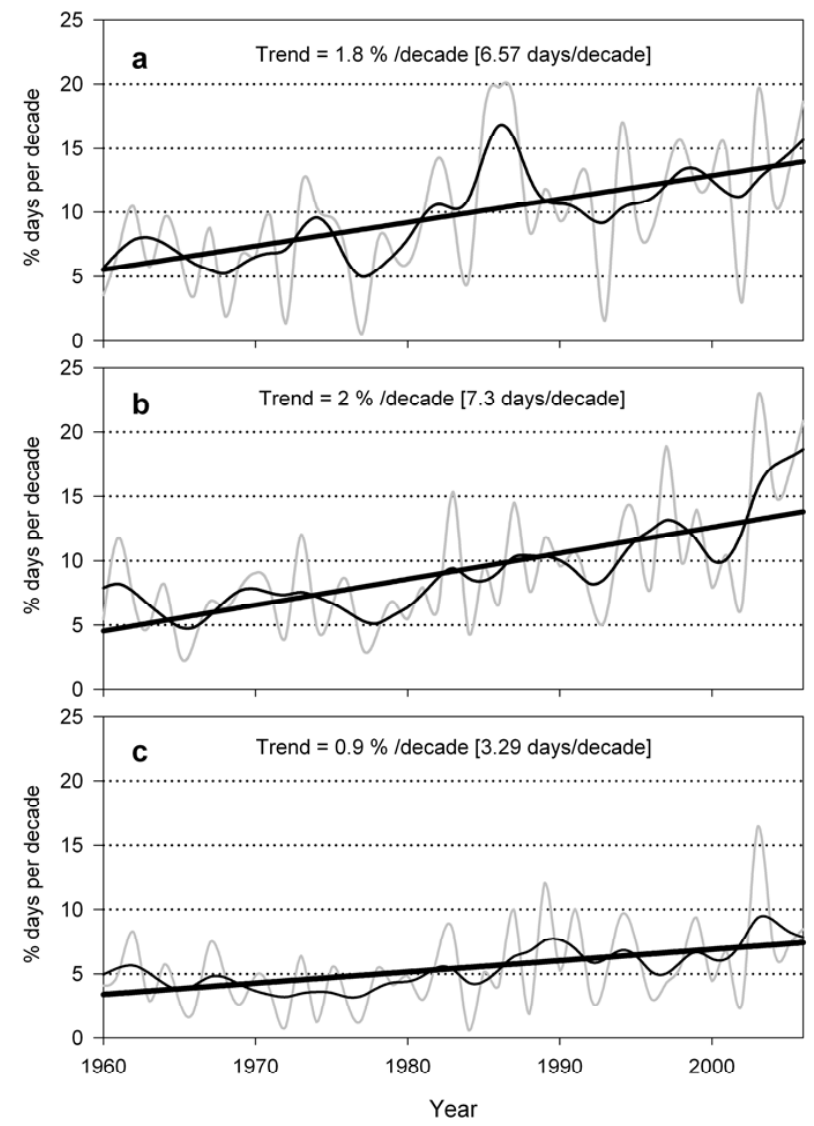

Fig. 6. Temporal evolution and trends in warm nights (TN90p) time series at three different observatories: (a) Blanes (Mediterranean station), (b) Bilbao airport (Cantabrian station), and (c) airport of Zaragoza (mainland station). The solid line represents the linear regression. The thin black line represents a 7-yr running mean. the only index that indicated a significant trend $(p<0.05)$ across much of the study domain $(69.5 \%$ of the observatories). This implies that trends in the probability distribution of the cold tail of temperature are more linked to the trends in the intensity of temperature than to the frequency of cold events. As indicated in Table 2, the number of observatories that experienced a downward tendency in the daytime cold indices (e.g. TX10p and ID0) was generally larger than those of night-time indices (e.g. TN10p, FD0, and CN). Nonetheless, the decrease in the night-time indices reached the statistical significance level $(p<0.05)$ in more observatories compared with day-time indices. For instance, cold nights (TN10p) and frost days (FD0) were statistically significant in 25.8 and $27.3 \%$ of observatories respectively, while cold days (TX10p) and ice days (ID0) reached the confidence level in only 19.5 and $16.4 \%$ of observatories, respectively. This finding indicates more warming in the cold tail of winter temperature than in the hot tail over the period from 1960 to 2006 .

Table 4 presents the association in the sign (direction) of the trend for each pair of cold temperature indices. As shown, there was a high level of consistency in the temporal evolution of the frequency indices, as revealed by coincidences in the sign of the trends. For instance, $84.4 \%$ of the observatories showed the same sign (direction) of changes in cold nights (TN10p) and frost days (FD0). Similarly, there was a high level of agreement ( $82.8 \%$ of the observatories) between the direction of trends in very cold days (TN1p), and both cold nights (TN10p) and cold days (TX10p). This suggests strong temporal consistency between indicators of the frequency of cold temperature. This high consistency also implies that variability in the frequency of cold extremes can be attributed to large-scale physical processes more than local conditions (e.g. topography). As indicated in Table 2, the annual low minimum temperature ( $\mathrm{TNn}$ ) showed higher 

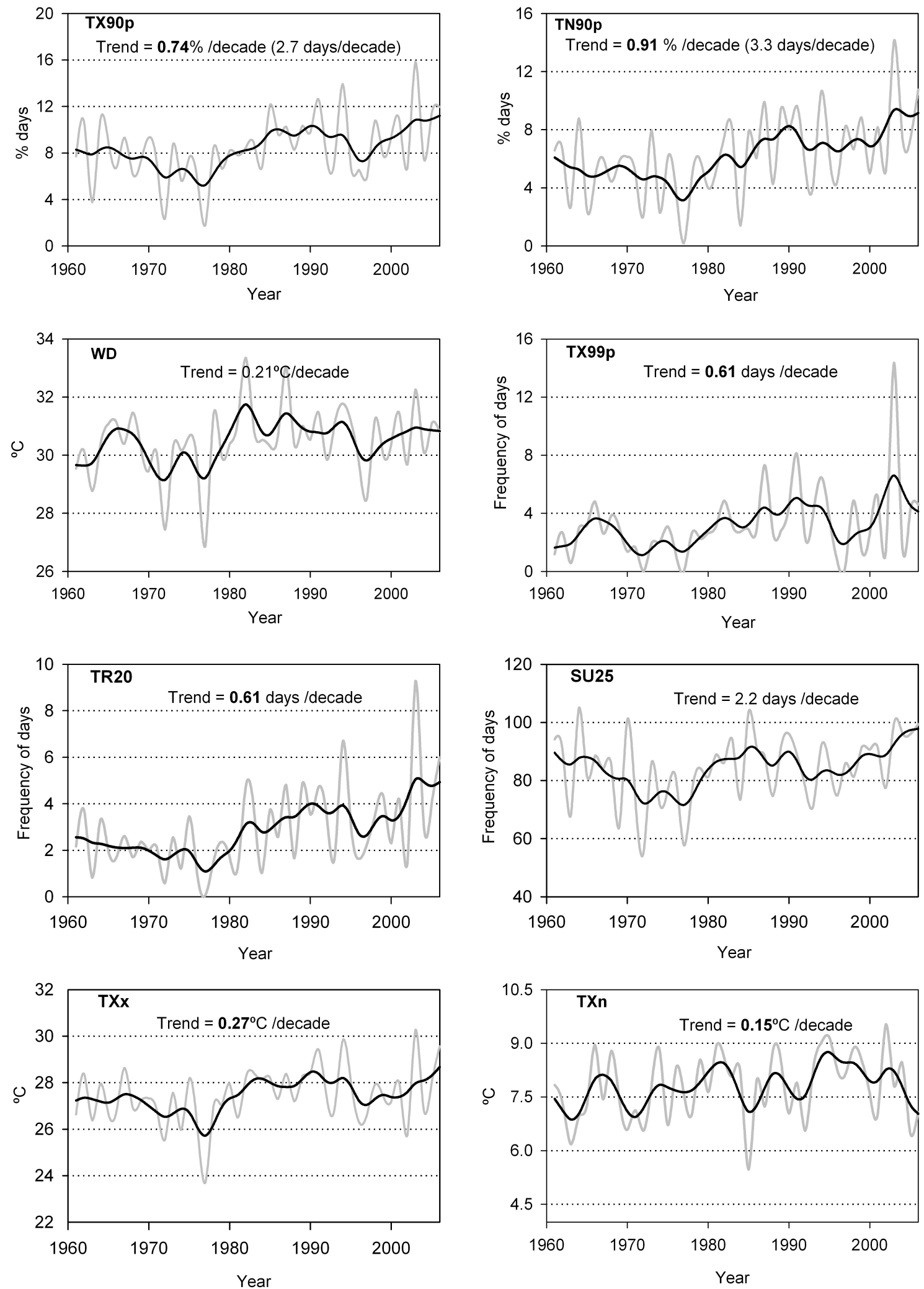

Fig. 7. Temporal evolution and trends in the regional series of hot extreme indices over the period 1960-2006. Only trend magnitudes given in bold numbers refer to significant trends (P-value $<0.05$ ), and black lines represent a 7-yr running mean. 

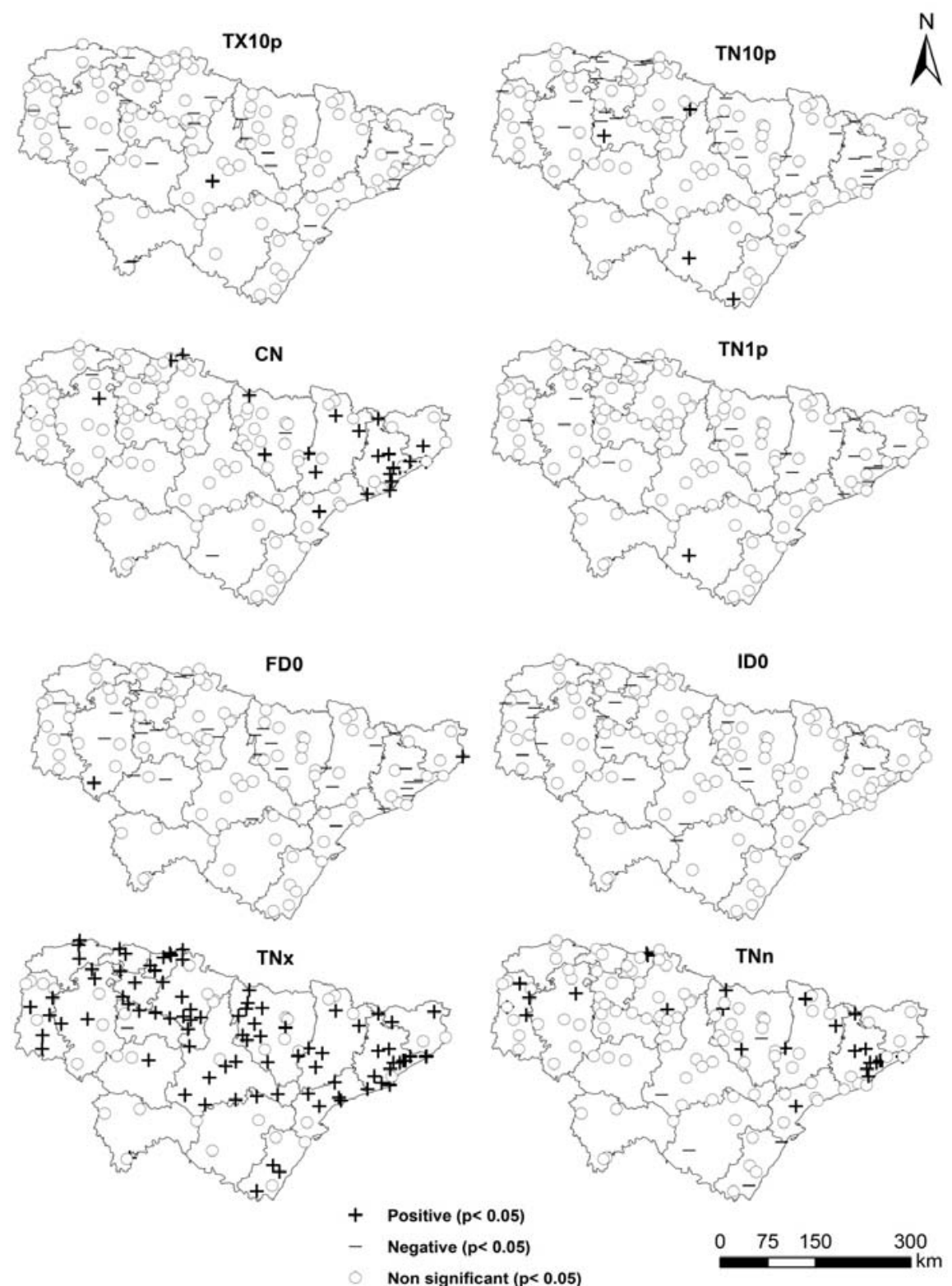

Fig. 8. The same as Fig. 5, but for cold extreme indices.

agreement with frequency indices, as compared with the annual high minimum temperature (TNx). This clearly confirms our previous finding regarding the rapid increase in the cold tail of temperature distribution during the cold season.

Figure 8 depicts the spatial distribution of the trends in cold extreme indices. In general, there were no marked spatial patterns across the study domain as trends are not evident in specific regions. However, there is a slight tendency to locate negative trends in inland observatories for cold days (TX10p), frost days (FD0) and very cold days (TN1p). By contrast, coldest night $(\mathrm{CN})$ and the annual low minimum $(\mathrm{TNn})$ revealed a spatial structure, whereby coastal observatories eastward showed rapid warming. In the same sense, the annual high minimum (TNx) showed a broad and spatially consistent pattern of positive trends, although this warming was markedly less evident in the southern and south-central portions of the study area.

Figure 9 illustrates the temporal evolution and trends in the regional series of cold temperature indices. Over the period from 1960 to 2006, the regionally weighted occurrence of cold days (TX10p), cold nights (TN10p), very cold days (TN1p), frost days (FD0) and ice days (ID0) decreased by $1.2,0.8,0.11,1.35$ and 0.19 days decade ${ }^{-1}$. Exceptionally, the annual high minimum temperature (TNx) showed a 

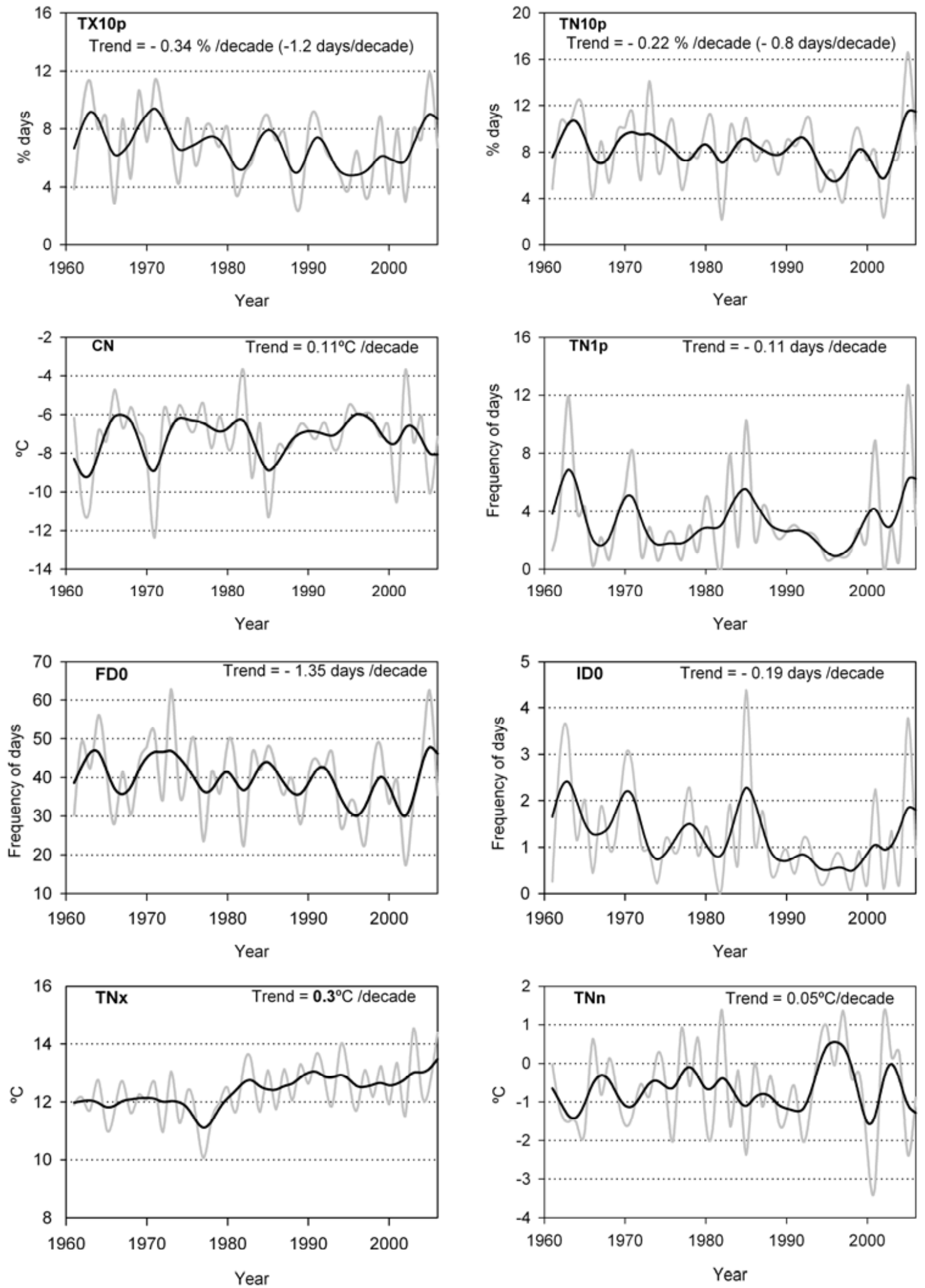

Fig. 9. The same as Fig. 7, but for cold extreme indices. 
Table 4. The association between pairs of cold and variability extreme indices with respect to the sign of the trends at the $95 \%$ level (statistically positive, statistically negative, and statistically insignificant). Numbers indicate sign coincidences for each pair of the indices.

\begin{tabular}{|c|c|c|c|c|c|c|c|c|c|c|c|c|c|}
\hline Index & TX10P & TN10P & FD0 & ID0 & $\mathrm{CN}$ & TN1P & TNX & TNn & $T_{\text {sums }}$ & Intra & Stdev & GSL & DTR \\
\hline TX10P & & 63.3 & 64.8 & 74.2 & 63.3 & 71.1 & 24.2 & 60.2 & 43.0 & 65.6 & 65.5 & 68.0 & 57.0 \\
\hline TN10P & & & 84.4 & 64.8 & 64.1 & 82.8 & 25.0 & 64.1 & 35.9 & 62.5 & 59.4 & 64.8 & 66.4 \\
\hline FD0 & & & & 67.2 & 63.3 & 82.8 & 23.4 & 63.3 & 35.9 & 58.6 & 60.2 & 62.5 & 64.8 \\
\hline ID0 & & & & & 66.4 & 73.4 & 26.6 & 64.8 & 43.8 & 71.1 & 68.8 & 71.9 & 60.2 \\
\hline $\mathrm{CN}$ & & & & & & 73.4 & 41.4 & 82.8 & 55.5 & 66.4 & 68.8 & 78.1 & 60.2 \\
\hline TN1P & & & & & & & 25.0 & 69.5 & 43.0 & 68.0 & 69.5 & 73.4 & 70.3 \\
\hline TNX & & & & & & & & 37.5 & 53.1 & 31.3 & 35.9 & 33.6 & 31.3 \\
\hline $\mathrm{TNn}$ & & & & & & & & & 49.2 & 62.5 & 64.8 & 78.1 & 54.7 \\
\hline$T_{\text {sums }}$ & & & & & & & & & & 53.9 & 56.3 & 53.9 & 44.5 \\
\hline Intra & & & & & & & & & & & 75.0 & 72.7 & 62.5 \\
\hline Stdev & & & & & & & & & & & & 71.9 & 61.7 \\
\hline GSL & & & & & & & & & & & & & 60.2 \\
\hline DTR & & & & & & & & & & & & & \\
\hline
\end{tabular}

statistically significant uptrend $\left(0.3^{\circ} \mathrm{C}\right.$ decade $\left.^{-1}\right)$. The low temporal variability of most of the cold indices at the regional scale agrees well with those observed at the individual sites. However, a visual inspection of the temporal evolution of these indices clearly reveals a multidecadal character. Temporarily, the inter-decadal variability of the cold indices is more apparent compared with the long-term changes. As shown in Fig. 10, a decadal comparison of the frequency of cold extremes over the period from 1960 to 2006 indicates that there were more colder events during the 1960s and 1970s (e.g. TX10p and ID0). However, they had markedly been less frequent during the last two decades. This high decadal variability could decrease the ability of the trend test to detect a long-term statistically significant linear trend over the period 1960-2006.

\subsubsection{Changes in variability extremes}

A summary of the Mann-Kendall results regarding trends in variability indices is given in Table 2 . In general, no trends were evident in most of the temperature variability indices $(p<0.05)$. Nevertheless, most of the observatories exhibited a clear upward tendency in indices of temperature sums $\left(T_{\text {sums }}\right)(93.8 \%)$, the standard deviation of mean temperature (Stdev) $(72.7 \%)$, and the growing season length (GSL) $(67.1 \%)$. The tendency in the diurnal temperature range (DTR) was mixed between positive $(49.2 \%)$ and negative $(50.8 \%)$. Among all indices, temperature sums $\left(T_{\text {sums }}\right)$ was the only indicator which showed a statistically significant trend $(p<0.05)$ in almost half of the observatories $(46.9 \%)$. Tables 3 and 4 summarize the association in trend significance between variability indices on the one hand and hot and cold extremes on the other. A comparison between Tables 3 and 4 suggests that variability indices showed a higher degree of agreement with cold extremes than with hot

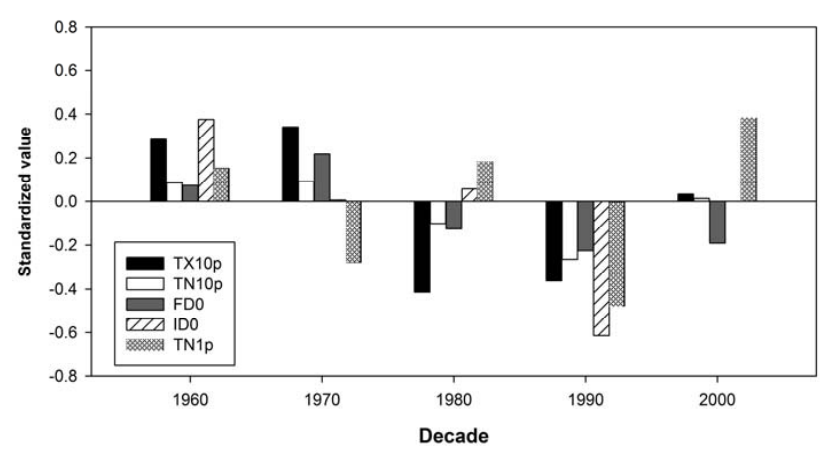

Fig. 10. Decadal variation of a set of the cold temperature frequency indices averaged for the whole study area. The annual number of events was standardized by their mean and standard deviation to account for different scale units of the indices.

extremes. For instance, the signs of the trends in the Interannual extreme temperature range (Intr) matched those of ice days (ID0), very cold days (TN1p), coldest night (CN), cold days (TX10p) and cold nights (TN10p) in 71.1, 68, 66.4, 65.5 and $62.5 \%$ of observatories, respectively. Contrarily, this coincides with the trends of warm nights (TN90p), tropical nights (TR20) and warm days (TX90p) only in 29.7, 47.7 and $50 \%$ of observatories, respectively. These results suggest that the behavior of variability indices in the study area is associated more with changes in the low tail of temperature distribution than in the hot tail. As expected, temperature sums ( $\left.T_{\text {sums }}\right)$ exhibited similar temporal patterns to hot extremes including: warm days (TX90p) and summer days (SU25) (71.9\%), the annual high maximum temperature (TXx) (68\%), and very hot days (TX99p) (65.6\%).

Figure 11 illustrates the spatial distribution of variability indices. Overall, the indices seem to be spatially 

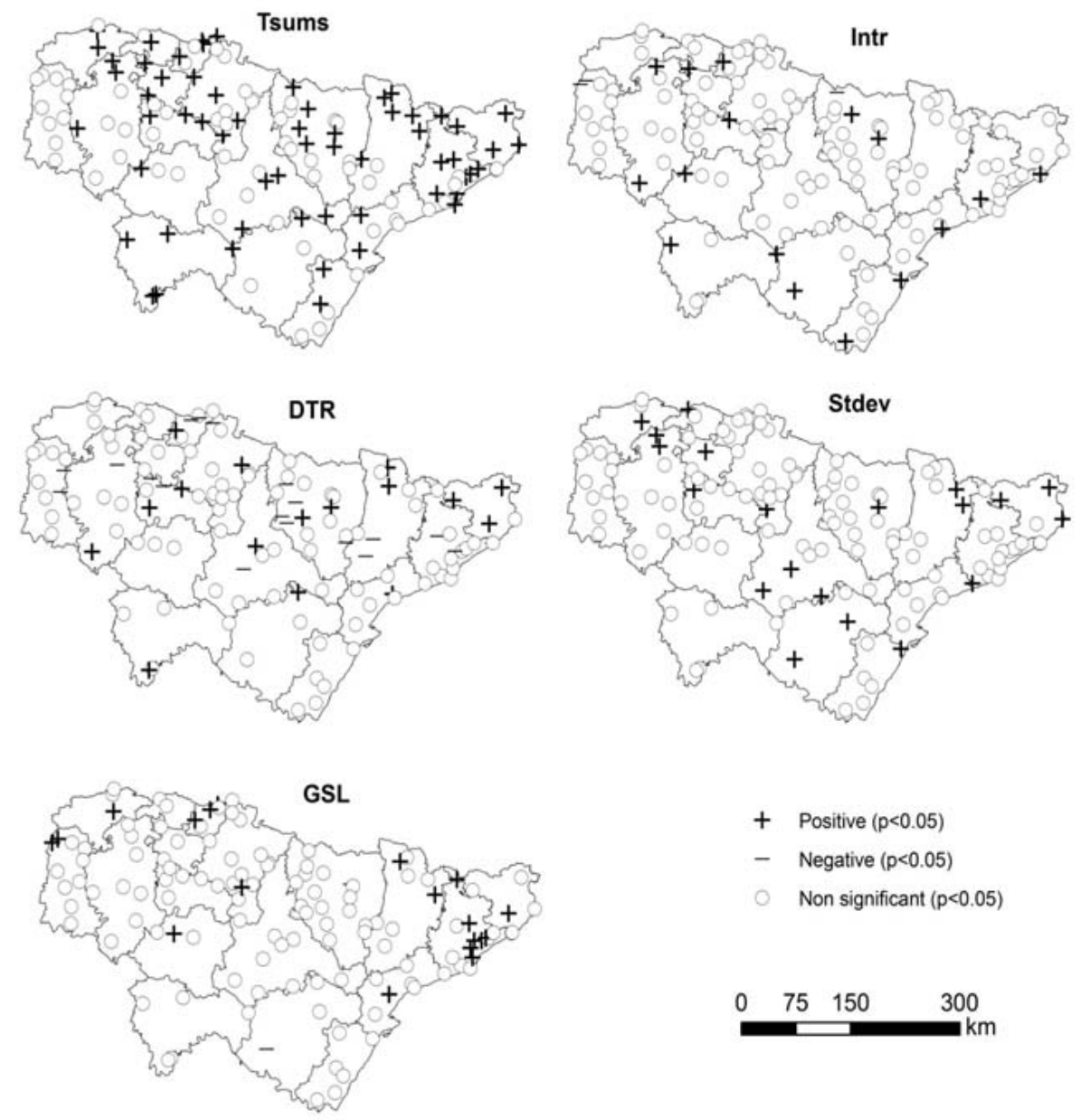

Fig. 11. The same as Fig. 5, but for variability indices.

independent, suggesting a very low spatial variability across the study area. However, some local differences can also be highlighted. For instance, most of the significant upward trends in the growing season length (GSL) tend to be located in the northeastern portions (Catalonia) and the highly elevated areas (e.g. the Pyrenees). Also, mainland observatories showed more significant trends in the diurnal temperature range (DTR) compared with coastal regions.

Figure 12 shows the temporal evolution and trends in the regional series of variability indices. All indices have no trends at the regional scale $(p<0.05)$. For instance, the regional series of the diurnal temperature range (DTR) experienced very weak warming during the period 1960-2006 $\left(0.02{ }^{\circ} \mathrm{C}\right.$ per decade). Also, the length of the growing season (GSL) showed insignificant increase by 0.33 days during the 47-yr. The only exception corresponds to temperature sums $\left(T_{\text {sums }}\right)$ which indicated a clear statistically significant uptrend $\left(118.8^{\circ} \mathrm{C}\right.$ decade $\left.^{-1}\right)$. In general, the overall insignificant trend observed for most of the regional series comes in agreement with the results obtained for the individual observatories.

\section{Discussion}

\subsection{Changes in hot extremes}

The results indicate an overall upward tendency in the frequency and intensity of hot extremes across much of the study area. This upward trend is generally compatible with previous findings (Frich et al., 2002; Klein Tank and Können; 2003; Alexander et al., 2006; IPCC, 2007). According to Alexander et al. (2006), there have been considerable changes in hot temperature extremes in the globe. As an example, more than $70 \%$ of the land-area observatories have shown statistically significant uptrend in warm nights over the period 1951-2003. For the Mediterranean region, numerous studies have assessed the impact of climate change on temperature extremes (e.g. Klein Tank and Können, 2003; Kostopoulou and Jones; 2005; Diffenbaugh et al., 2007; Hertig et al., 2010). Among them, Klein Tank and Können (2003) found a significant positive trend in the warm tails of the European daily temperature over the second half of the 20th century. The same finding has recently 

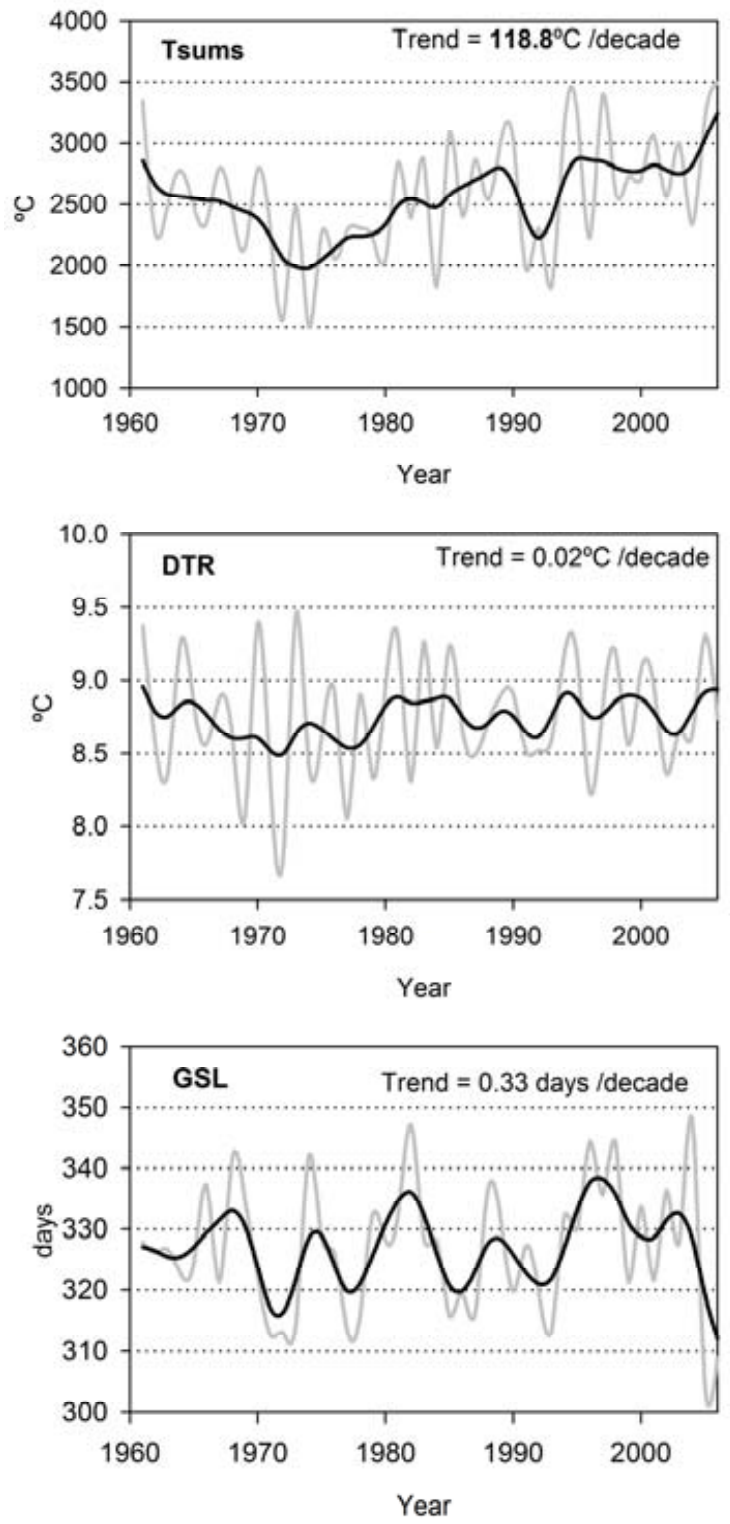

Fig. 12. The same as Fig. 7, but for variability indices.

been confirmed by Kostopoulou and Jones (2005) for the Eastern Mediterranean and by Politano (2008) and Hertig et al. (2010) for the Western Mediterranean. For the Iberian Peninsula, there has been a limited number of studies that examined the behavior of hot extremes. Brunet et al. (2007b) suggested evidence of larger changes in high temperature extremes in Spain from 1955 to 2006. Similarly, Della-Marta et al. (2007) pointed out that the temperature of Western Europe, including Iberia, has become more extreme, with the increase being more confined to summer.

The increase in frequency and severity of hot temperature extremes can be linked mainly to the rapid warming in maximum temperature compared with minimum temperature. In
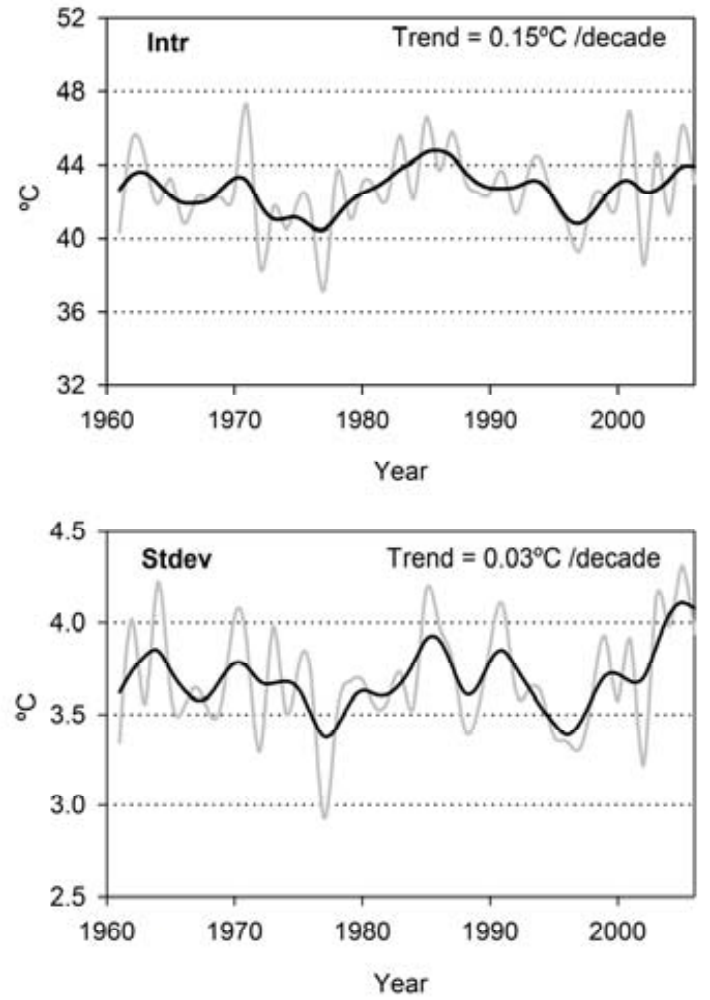

their study covering all of Spain, Brunet et al. (2007b) found higher rates of change in maximum temperature rather than in minimum temperature over the period 1850-2005 $\left(0.11^{\circ}\right.$ versus $\left.0.08^{\circ} \mathrm{Cdecade}^{-1}\right)$. The same finding has recently been confirmed by El Kenawy et al. (2011) for the study area. According to this study, the most remarkable warming in daily mean temperature from 1960 to 2006 occurred during hot seasons: spring $\left(0.66^{\circ} \mathrm{Cdecade}^{-1}\right)$ and summer $\left(0.41^{\circ} \mathrm{C}_{\text {decade }}{ }^{-1}\right)$.

Spatially, there is a roughly contrasting coastal-continental pattern of hot extremes, whereby the trends were more pronounced along the Mediterranean Sea and the Cantabrian Sea while warming was less evident in mainland areas. This 


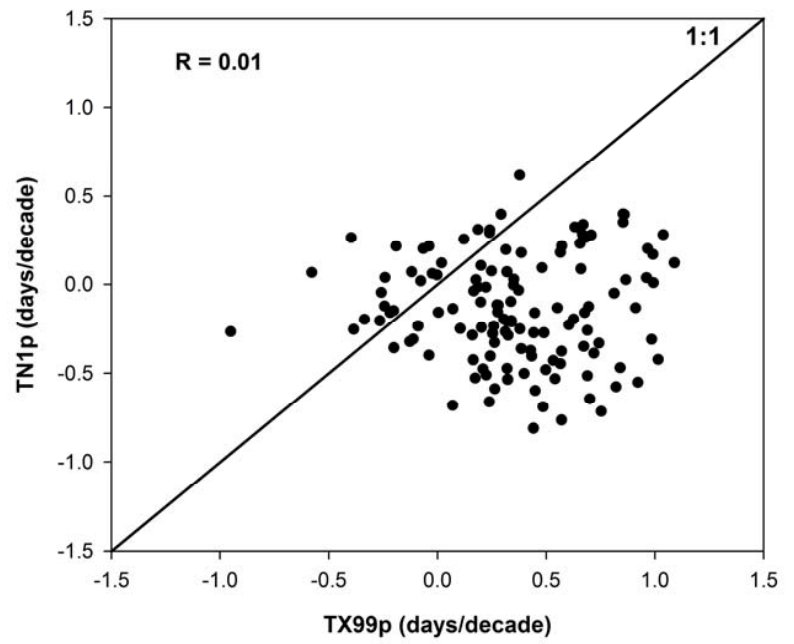

Fig. 13. Scatter plot of the relationship between the observed trends in TX99p and TN1p.

feature probably suggests a linkage between hot extremes and sea surface temperature (SST). Previous studies reported a strong relationship between temperature extremes and SST. For example, Black and Sutton (2006) linked the 2003 European heat wave with variations in SST anomalies of both the Mediterranean Sea and the Indian Ocean. Given the notable increase in the frequency and severity of hot temperature events, which could have significant implications for hydrology, ecology and agriculture, this kind of research could provide a concrete base for a better understanding of the spatial and temporal variability of hot extremes at this sub-regional scale, as induced by variability in these driving forces. In the same context, our findings showed more warming in hot extremes close to the coasts. This result comes in contrast to the simulations of some global climate models (GCMs), which documented less warming near the coasts compared to continental areas (IPCC, 2007). Thus, it is also important to assess the impact of closed water bodies on hot extremes by means of simulations from different atmosphere-ocean climate models.

\subsection{Changes in cold extremes}

The Mann-Kendall results confirm that most of the cold temperature extremes showed a decreasing but statistically insignificant trend $(p<0.05)$. The only exception corresponds to the annual high minimum temperature (TNx), which showed an upward trend of $0.3^{\circ} \mathrm{C}$ per decade at the regional scale. The uptrend in $\mathrm{TNx}$ can be linked to the increase in day-night temperature during the summer season, which has been confirmed at both the regional (Zhang et al., 2005) and the global scales (Frich et al., 2002). A number of studies worldwide showed little change in cold extremes. For example, New et al. (2006) pointed out that indices related to the minimum temperature for southern Africa were less warming compared with those of maximum temperature. In the study domain maximum temperature has increased faster than minimum temperature over the whole period 19602006 (El Kenawy et al., 2011), which suggests lower variance in the cold tail of temperature distribution. However, our findings are still in contrast with other studies. In central and south Asia, Klein Tank et al. (2006), as an example, reported that most cold temperature indices exhibited significant warming in the period from 1961 to 2000. Also, Moberg et al. (2006) gave consistent conclusions in their study of trends in daily temperature extremes in Europe. Similarly, Brunet et al. (2007b) reported a decrease in cold temperature extremes in recent decades across much of Spain. In this context, it is worthwhile indicating that the occurrence of cold temperature extremes showed a clear decadal variation in the study area. Cold events were more frequent during the 1960s and 1970s. This situation has been reversed from the late 1970s onwards, due to the rapid warming in minimum temperature in the last two decades (El Kenawy et al., 2011). This observation agrees well with the results of Bermejo and Ancell (2009), who reported a significant increase in minimum temperature across Spain after 1980. Accordingly, it is important to seek out the driving forces that can describe the interdecadal variability of cold extremes. This can include certain physical factors such as atmospheric circulation and sea surface temperature.

\subsection{Changes in variability extremes}

Similar to cold extremes, trends in variability extremes were less prevalent, since insignificant trends were noted for most of indices, with the exception of temperature sums $\left(T_{\text {sums }}\right)$. For instance, the growing season length (GSL) has significantly increased in only $14.8 \%$ of observatories. This finding compares well with Alexander et al. (2006), who indicated that around 16.8 of land observatories worldwide have experienced significant positive trends in the growing season length (GSL). In the study area, the less temporal variability of most of the indices can largely be explained by the inconsistence changes in maximum and minimum temperature over the past few decades. The evolution of the diurnal temperature range (DTR) is a clear example that summarizes the asymmetric evolution of both maximum and minimum temperature. As noted by many studies (Dai et al., 1997; Easterling et al., 2000), the globe has experienced a general negative trend in diurnal temperature range (DTR) that is largely a consequence of the rapid increase in minimum temperatures rather than maximum temperatures. However, this trend has not been confirmed in certain regions worldwide, such as the British Isles (Horton, 1995), Italy (Brunetti et al., 2000), and South Africa (Kruger and Shongwe, 2004). In this work, the trends in DTR were mixed between positive $(49.2 \%)$ and negative $(50.8 \%)$, insignificant in $71.9 \%$ of observatories. This behavior is mostly due to the rapid warming 
of maximum temperature in recent decades, which is inconsistent with changes in minimum temperature over the same period. Other regions in the Iberian Peninsula including the central Ebro valley (Abaurrea et al., 2001), mainland Spain (Folland et al., 2001), and the whole Spain (Brunet et al., 2007a) have also experienced positive DTR. However, it may be noteworthy that the findings of different studies on DTR variability must cautiously be taken into account given that the results at the annual scale may vary considerably from those obtained at the seasonal scale. Also, the results can vary greatly according to the period of investigation.

The evolution of the Intra-annual extreme temperature range (Intr) index can also be explained by the asymmetric evolution of very hot days (TX99p) and very cold days (TN1p) indices. Although these two indices summarize the evolution of the most extreme events in terms of their frequency, they can, to some extent, provide a good indication of the variability in the Intra-annual extreme temperature range (Intr). The relationship between trends in both TX99p and TN1p is given in Fig. 13, which are not linearly wellfitted $(R=0.01)$. This weak dependence between the two indices can be seen in the context that the frequency of very hot days (TX99P) showed a strong uptrend, more highlighted over the last few decades (Fig. 7). In contrast, the decrease in the frequency of very cold days (TN1p) did not occur at the same rate (Fig. 9).

\section{Summary and conclusion}

Characterization of extreme temperature events is important for studies of climate change, hydrological modeling and simulation, and agriculture. Using a 47-yr daily dataset of maximum and minimum temperature from 128 meteorological observatories, the spatial and temporal variability of temperature extremes were analyzed in northeastern Spain over the period 1960-2006. The trends were assessed by means of the Mann-Kendall statistic after the removal of the significant lag-1 serial correlation using a prewhitening procedure.

The trend analysis of extreme events suggests that there has been an increase in the frequency and intensity of hot extremes (e.g. TX90p, TN90p, TR20 and TXx) rather than in cold extremes (e.g.TN10P, FD0, ID0 and TNn). The indices with significant trends were less for cold events than for hot events, suggesting an obvious shift toward more hot extremes in the study area. This upward trend in hot extremes has been more pronounced over the last two decades, corresponding to the rapid warming in the mean maximum temperature. On the other hand, most of the cold extremes exhibited a downward tendency, significant in few indices (e.g. TNx and TNn). Changes in cold extremes were largely related to the magnitude (e.g. $\mathrm{CN}, \mathrm{TNx}$, and $\mathrm{TNn}$ ) rather than to the frequency of cold events (e.g. TX10p, TN10p, ID0, and FD0). Similar to cold extremes, no evidence of trends was exhibited for most of the temperature variability indices (e.g. DTR and Intr). Overall, the study area seems to be more sensitive to global warming during the warm season, while it shows less sensitivity to this warming during the cold season.

A comparison of the trends in hot and cold temperature extremes indicates that the impact of climate change on temperature is mainly accompanied by a higher shift in the hot tail rather than in the cold tail. The major changes in temperature extremes in NE Spain are focused on the frequency and intensity of hot extremes. This finding fits well with the results of Klein Tank and Können (2003) for Europe, Politano (2008) for the Mediterranean, Beniston (2009) for Switzerland and Brunet et al. (2007b) for peninsular Spain.

There is a lack of long-term studies on extreme temperature events in specific regions in the Iberian Peninsula. Given the high spatial and temporal scales of our dataset, the present study represents a significant contribution to the understanding of the spatial and temporal changes of temperature extremes. The findings of this work can thus be useful for various applications in hydrology, ecology and agriculture. Given that the coastal areas showed stronger and more significant increase in indices related to maximum temperature, future research should investigate the influence of the SST and atmospheric circulation on the frequency, intensity, and persistency of high frequency temperature changes.

Acknowledgements. We are indebted to the anonymous reviewers for their constructive comments which were most helpful in improving the paper. We would like to thank the "Agencia Estatal de Meteorología" for providing the temperature data used in this study. This work has been supported by the research projects CGL2008-01189/BTE and CGL2006-11619/HID financed by the Spanish Commission of Science and Technology and FEDER, EUROGEOSS (FP7-ENV-2008-1-226487) and ACQWA (FP7ENV-2007-1- 212250) financed by the VII Framework Programme of the European Commission, "Las sequías climáticas en la cuenca del Ebro y su respuesta hidrológica" and "La nieve en el Pirineo aragonés: Distribución espacial y su respuesta a las condiciones climática" Financed by "Obra Social La Caixa" and the Aragón Government.

Edited by: R. García-Herrera

Reviewed by: three anonymous referees

\section{References}

Abaurrea, J., Asin, J., Erdozain, O., and Fernández, E.: Climate variability analysis of temperature series in the Medium Ebro River Basin, in: Detecting and Modeling Regional Climate Change, edited by: Brunet, M. and Lopez, D., 109-118, Springer, New York, 2001.

Alexander, L. V., Zhang, X., Peterson, T. C., Caesar, J., Gleason, B., Klein Tank, A. M. G., Haylock, M., Collins, D., Trewin, B., Rahimzadeh, F., Tagipour, A., Ambenje, P., Rupa Kumar, K., Revadekar, J., and Griffiths, G.: Global observed changes in daily climate extremes of temperature and precipitation, J. Geophys. Res. Atmos., 111, D05109, doi:10.1029/2005JD006290, 2006. 
Alexandersson, H.: A homogeneity test applied to precipitation data, Int. J. Climatol., 6, 661-675, 1986.

Begueria-Portugues, S. and Vicente Serrano, S. M.: Mapping the hazard of extreme rainfall by peaks-over-threshold extreme value analysis and spatial regression techniques, J. Appl. Meteorol., 45, 108-124, 2006.

Beniston, M.: Decadal-scale changes in the tails of probability distribution functions of climate variables in Switzerland, Int. J. Climatol., 29, 1362-1368, 2009.

Bermejo, M. and Ancell, R.: Observed changes in extreme temperatures over Spain during 1957-2002 using Weather Types, Revista de Climatologia, 9, 45-61, 2009.

Black, E. and Sutton, R.: The influence of oceanic conditions on the hot European summer of 2003, Clim. Dynam., 28, 53-66, 2006.

Box, G. and Jenkins, G.: Time series analysis: Forecasting and control, San Francisco, CA, Holden-Day, 575 pp., 1970.

Brown, S. J., Caesar J., and Ferro, C. A. T.: Global changes in extreme daily temperature since 1950, J. Geophys. Res. Atmos., 113, D05115, doi:10.1029/2006JD008091, 2008.

Brunet, M., Jones, P. D., Sigro, J., Saladie, O., Aguilar E., Moberg, A., Della-Marta, P. M., Lister D., Walther, A., and Lopez, D.: Temporal and spatial temperature variability and change over Spain during 1850-2005, J. Geophys. Res. Atmos., 112, D12117, doi:10.1029/2006JD008249, 2007a.

Brunet, M., Sigro, J., Jones, P. D., Saladie, O., Aguilar, E., Moberg, A., and Walter, A.: Long- term changes in extreme temperatures and precipitation in Spain, Contribution to Science, 3, 331-342, 2007b.

Brunetti, M., Buffoni, L., Maugeri, M., and Nanni, T.; Trends of minimum and maximum daily temperatures in Italy from 1865 to 1996, Theor. Appl. Climatol., 66, 49-60, 2000.

Burgueño, A., Lana, X., and Serra, C.: Significant hot and cold events at the Fabra Observatory, Barcelona (NE Spain), Theor. Appl. Climatol., 71, 141-156, 2002.

Burn, D. H. and Cunderlik, J. M..: Hydrological trends and variability in the Liard River basin, Hydrol. Sci. J., 49(1), 53-67, 2004.

Caussinus, H. and Mestre, O.: Detection and correction of artificial shifts in climate series, Appl. Stat., 53, 405-425, 2004.

Choi, G., Collins, D., Ren, G., Trewin, B., Baldi, M., Fukuda, Y., Afzaal, M., Pianmana, T., Gomboluudev, P., Huong, P. T., Lias, N., Kwon, W. T., Boo, K. O., Cha, Y. M., and Zhou Y.: Changes in means and extreme events of temperature and precipitation in the Asia-Pacific Network region, 1955-2007, Int. J. Climatol., 29, 1906-1925, 2009.

Christopher, S. and Gerd, J.: Hot news from summer 2003, Nature, 432, 559-560, 2003

Ciais, Ph., Reichstein, M., Viovy, N., Granier, A., Ogée, J., Allard, V., Aubinet, M., Buchmann, N., Bernhofer, Chr., Carrara, A., Chevallier, F., De Noblet, N., Friend, A. D., Friedlingstein, P., Grünwald, T., Heinesch, B., Keronen, P., Knohl, A., Krinner, G., Loustau, D., Manca, G., Matteucci, G., Miglietta, F., Ourcival, J. M., Papale, D., Pilegaard, K., Rambal, S., Seufert, G., Soussana, J. F., Sanz, M. J., Schulze, E. D., Vesala, T., and Valentini, R.: Europe-wide reduction in primary productivity caused by the heat and drought in 2003, Nature, 437(7058), 529-534, 2005.

Costa, A. C. and Soares, A.: Trends in extreme precipitation indices derived from a daily rainfall database for the South of Portugal, Int. J. Climatol., 29, 1956-1975, 2009.
Dai, A., Del Genio., A. D., and Fung, I. Y.: Maximum and minimum temperature trends for the globe, Nature, 386, 665-667, 1997.

Della-Marta, P. M., Haylock, M. R., Luterbacher, J., and Wanner, H.: Doubled length of western European summer heat waves since 1880, J. Geophys. Res., 112, D15103, doi:10.1029/2007JD008510, 2007.

Douglas, E. M., Vogel, R. M., and Kroll, C. N.: Trends in floods and low flows in the United States: impact of spatial correlation, J. Hydrol., 240, 90-105, 2000.

Easterling, D. R. and Peterson, T. C.: A new method of detecting undocumented discontinuities in climatological time series, Int. J. Climatol., 15, 369-377, 1995.

Easterling, D. R., Meehl, G. A., Parmesan, C., Changnon, S. A., Karl, T. R., and Mearns, L. O.: Climate extremes: observations, modeling, and impacts, Science, 289, 2068-2074, 2000.

El Kenawy, A., López-Moreno, I, Vicente-Serrano, S. M., and Stepanek, P.: An assessment of the role of homogenization protocols in the performance of daily temperature series and trends: application to northeastern Spain, Int. J. Climatol., in review, 2010.

El Kenawy, A., López-Moreno, I., and Vicente-Serrano, S. M.: Trend and variability of temperature in northeastern Spain (1920-2006): linkage to atmospheric circulation, Atmos. Res., in review, 2011

Folland, C. K., Karl, T. R., Christy, J. R., Clarke, R. A., Gruza, G. V., Jouzel, J., Mann, M. E., Oerlemans, J., Salinger M. J.a and Wang, S. W.: Observed Climate Variability and Change, in: Climate Change (2001): The Scientific Basis. Contribution of Working Group I to the Third Assessment Report of the Intergovernmental Panel on Climate Change, edited by: Houghton, J. T., Ding, Y., Griggs, D. J., Noguer, M., van der Linden, P. J., Dai, X., Maskell, K., and Johnson, C. A., Cambridge Univ. Press, 2001.

Frich, P., Alexander, L. V., Della-Marta, P., Gleason, B., Haylock, M., Klein Tank, A. M. G., and Peterson, T.: Observed coherent changes in climatic extremes during the second half of the twentieth century, Clim. Res., 19, 193-212, 2002.

García-Herrera, R., Díaz, J., Trigo, R. M., and Hernández, E. Extreme summer temperatures in Iberia: health impacts and associated synoptic conditions, Ann. Geophys., 23, 239-251, doi:10.5194/angeo-23-239-2005, 2005.

Horton, B.: The geographical distribution of changes in maximum and minimum temperatures, Atmos. Res., 37, 101-117, 1995.

IPCC, Climate Change: The Physical Science Basis, Contribution of Working Group I to the Fourth Assessment Report of the Intergovernmental Panel on Climate Change, edietd by: Solomon, S., Qin, D., Manning, M., Chen, Z., Marquis, M., Averyt, K. B., Tignor, M., and Miller, H. L., Cambridge University Press, Cambridge, United Kingdom and New York, NY, USA, 996 pp., 2007.

Jones, P. D. and Hulme, M.: Calculating regional climatic time series for temperature and precipitation: methods and illustrations, Int. J. Climatol., 16, 361-377, 1996.

Jones, P. D., Jones, R. N., Nicholls, N., and Sexton, D. H. M.: Global temperature change and its uncertainties since 1861, Geophys. Res. Lett., 28, 2621-2624, 2001.

Katz, R. W. and Brown, B. G.: Extreme events in a changing climate: variability is more important than averages, Climatic 
Change, 21, 289-302, 1992.

Klein Tank, A. M. G. and Konnen, G. P.: Trends in indices of daily temperature and precipitation extremes in Europe, 1946-99, J. Climate, 16, 3665-3680, 2003.

Klein Tank, A. M. G., Peterson, T. C., Quadir, D. A., Dorji, S., Zou, X., Tang, H., Santhosh, K., Joshi, U. R., Jaswal, A. K., Kolli, R. K., Sikder, A., Deshpande, N. R., Revadekar, J. V., Yeleuova, K., Vandasheva, S., Faleyeva, M., Gomboluudev, P., Budhathoki, K. P., Hussain, A., Afzaal, M., Chandrapala, L., Anvar, H., Amanmurad, D., Asanova, V. S., Jones, P. D., New, M. G., and Spektorman, T.: Changes in daily temperature and precipitation extremes in central and south Asia, J. Geophys. Res., 111, D16105, doi:10.1029/2005JD006316, 2006.

Kostopoulou, E. and Jones, P.: Assessment of climate extremes in Eastern Mediterranean, Meteorol. Atmos. Phys., 89, 69-85, 2005.

Kruger, A. C. and Shongwe, S.: Temperature trends in South Africa, 1960-2003, Int. J. Climatol., 24, 1929-1945, 2004.

Kuglitsch, F. G., Toreti, A., Xoplaki, E., Della-Marta, P. M., Zerefos, C. S., Türkes, M., and Luterbacher, J.: Heat Wave Changes in the Eastern Mediterranean since 1960, Geophys. Res. Lett., 37, L04802, doi:10.1029/2009GL041841, 2010.

Lana, X. and Burgueño, A.: Extreme winter minimum temperatures in Catalonia (northeast Spain): expected values and their spatial distribution, Int. J. Climatol., 16, 1365-1378, 1996.

Lettenmaier, D. P., Wood, E. F., and Wallis, J. R.: Hydroclimatological trends in the continental Unied States, J. Climate, 7, 586-607, 1994.

López-Moreno, J. I., Vicente-Serrano, S. M., Angulo-Martínez, M., Beguería, S., and Kenawy, A.: Trends in daily precipitation on the northeastern Iberian Peninsula, 1955-2006, Int. J. Climatol., 30, 1026-1041, 2010.

Luterbacher, J., Dietrich, D., Xoplaki, E., Grosjean, M., and Wanner, H.: European seasonal and annual temperature variability, trends, and extremes since 1500, Nature, 303, 1499-1503, 2004.

Maheras, P., Xoplaki, E., Davies, T., Martin-Vide, J., Bariendos, M., and Alcoforado, M.: Warm and cold monthly anomalies across the Mediterranean basin and their relationship with circulation; 1860-1990, Int. J. Climatol., 19, 1697-1715, 1999.

Martin-Vide, J.: Spatial distribution of a daily precipitation concentration index in peninsular Spain, Int. J. Climatol., 24, 959-971, 2004.

Miro, J. J., Estrela, M. J., and Milan, M.: Summer temperature trends in a Mediterranean area (Valencia region), Int. J. Climatol., 26, 1051-1073, 2006.

Moberg, A. and Jones, P. D.: Trends in indices for extremes in daily temperature and precipitation in central and Western Europe 1901-1999, Int. J. Climatol., 25, 1173-1188, 2005.

Moberg, A., Jones, P. D., Lister, D., Walther, A., Brunet, M., Jacobeit, J., Alexander, L. V., Della-Marta, P. M., Luterbacher, J., Yiou, P., Chen, D., Klein Tank, A. M. G., et al.: Indices for daily temperature and precipitation extremes in Europe analyzed for the period 1901-2000, J. Geophys. Res., 111, D22106, doi:10.1029/2006JD007103, 2006.

New, M., Hewitson, B., Stephenson, D. B., Tsiga, A., Kruger, A., Manhique, A., Gomez, B., Coelho, C. A. S., Masisi, D. N., Kululanga, E., Mbambalala, E., Adesina, F., Saleh, H., Kanyanga, J., Adosi, J., Bulane, L., Fortunata, L., Mdoka, M. L., and Lajoie, R.: Evidence of trends in daily climate extremes over south- ern and West Africa, J. Geophys. Res. Atmos., 111, D14102, doi:10.1029/2005JD006289, 2006.

Patz, J. A., Campbell-Lendrum, D., Holloway, T., and Foley, J. A.: Impact of regional climate change on human health, Nature, 438, 310-317, 2005.

Peterson, T. C. and Easterling, D. R.: Creation of homogeneous composite climatological reference series, Int. J. Climatol., 14, 671-680, 1994.

Politano, L.: Extreme temperature events in the Mediterranean, MA thesis, Institute of Geography, University of Bern, 80 pp., 2008.

Prieto, L., Garcia-Herrera, R., Diaz, J., Hernandez, E., and Del Teso, T.: Minimum extreme temperatures over Peninsular Spain, Glob. Planet. Change, 44, 59-71, 2004.

Rodriguez-Puebla, C., Encinas, A. H., García-Casado, L. A., and Nieto, S.: Trends in warm days and cold nights over the Iberian Peninsula: relationships to large-scale variables, Climate Change, 100, 667-684, doi:10.1007/s10584-009-9721-0, 2009.

Schindler, D. W.: Widespread Effects of Climatic Warming on Freshwater Ecosystems in North America, Hydrol. Process., 11, 1043-1067, 1997.

Sheng, J. and Zwiers, F.: An improved scheme for time-dependent boundary conditions in atmospheric general circulation models, Clim. Dynam., 14, 609-613, 1998.

Stepanek, P.: AnClim- software for time series analysis (for windows), Department of Geography, Faculty of Natural Sciences, Masaryk University: Brno, 1.47 MB, 2004.

Stepanek, P., Zahradníèek, P., and Skalák, P.: Data quality control and homogenization of the air temperature and precipitation series in the Czech Republic in the period 1961-2007, Adv. Sci. Res., 3, 23-26, 2009.

Vincent, L. A.: A technique for the identification of inhomogeneities in Canadian temperature series, J. Climate, 11, 10941104, 1998.

Vincent, L. A., Peterson, T. C., Barros, V. R., Marino, M. B., Rusticucci, M., Carrasco, G., Ramirez, E., Alves, L. M., Ambrizzi, T., Berlato, M. A., Grimm, A. M., Marengo, J. A., Molion, L., Moncunill, D. F., Rebello, E., Anunciação, Y. M. T., Quintana, J., Santos, J. L., Baez, J., Coronel, G., Garcia, J., Trebejo, I., Bidegain, M., Haylock, M. R., and Karoly, D.: Observed trends in indices of daily temperature extremes in South America 19602000, J. Climate, 18, 5011-5023, 2005.

Vincent, L. A., Aguilar, E., Saindou, M., Hassane, A. F., Jumaux, G., Roy, D., Booneeady, P., Virasami, R., Randriamarolaza, L. Y. A., Faniriantsoa, F. R., Amelie, V., Seeward, H., and Montfraix, B.: Observed trends in indices of daily and extreme temperature and precipitation for the Countries of the Western Indian Ocean, 1961-2008, J. Geophys. Res., 116, D10108, doi:10.1029/2010JD015303, 2010.

WMO: Climatic change, Technical note, World Meteorological Organization, Geneva, 79 pp., 1966.

WMO: Climate Data and Monitoring: Guidelines on Analysis of extremes in a changing climate in support of informed decisions for adaptation, WCDMP No. 72, WMO/TD-No. 1500, 52 pp., 2009.

Yue, S. and Wang, C. Y.: Applicability of prewhitening to eliminate the influence of serial correlation on the Mann-Kendall test, Water Resour. Res., 38(6), 1068, doi:10.1029/2001WR000861, 2002.

Yue, S. and Wang, C. Y.: The Mann-Kendall test modified by effec- 
tive sample size to detect trend in serially correlated hydrological series, Water Resour. Manag., 18(3), 201-218, 2004.

Yue, S., Pilon, P., Phinney, B., and Cavadias, G.: The influence of correlation on the ability to detect trend in hydrological series, Hydrol. Process., 16, 1808-1829, 2002.

Zhang, X., Vincent, L. A., Hogg, W. D., and Niitsoo, A.: Temperature and precipitation trends in Canada during the 20th century, Atmos. Ocean, 38(3), 395-429, 2000.
Zhang, X., Aguilar, E., Sensoy, S., Melkonyan, H., Tagiyeva, U., Ahmed, N., Kutaladze, N., Rahimzadeh, F., Taghipour, A., Hantosh, T. H., Alpert, P., Semawi, M., Ali, M. K., Al-Shabibi, M. H. S., Al-Oulan, Z., Zatari, T., Al Dean Khelet, I., Hamoud, S., Sagir, R., Demircan, M., Eken, M., Adiguzel, M., Alexander, L., Peterson, T. C., and Wallis, T.: Trends in Middle East climate extreme indices from 1950 to 2003, J. Geophys. Res. Atmos., 110, D22104, doi:10.1029/2005JD006181, 2005. 